$12-2003$

\title{
Getting It Right: The MISE Approach to Professional Development
}

Thomas B. Corcoran

University of Pennsylvania, tomc@gse.upenn.edu

Siobhan McVay

Kate Riordan

Follow this and additional works at: https://repository.upenn.edu/cpre_researchreports

Part of the Curriculum and Instruction Commons, Education Policy Commons, Science and Mathematics Education Commons, and the Teacher Education and Professional Development Commons

\section{Recommended Citation}

Corcoran, Thomas B.; McVay, Siobhan; and Riordan, Kate. (2003). Getting It Right: The MISE Approach to Professional Development. CPRE Research Reports.

Retrieved from https://repository.upenn.edu/cpre_researchreports/42

View on the CPRE website.

This paper is posted at ScholarlyCommons. https://repository.upenn.edu/cpre_researchreports/42

For more information, please contact repository@pobox.upenn.edu. 


\title{
Getting It Right: The MISE Approach to Professional Development
}

\author{
Abstract \\ With an initial 10-year commitment from Merck \& Co., Inc. the Merck Institute for Science Education \\ (MISE) was founded in 1993 to demonstrate that virtually all students could reach high levels of scientific \\ literacy. Shortly thereafter, MISE formed partnerships with four public school districts -- Linden, Rahway, \\ and Readington Township in New Jersey, and North Penn in Pennsylvania -- where Merck has major \\ facilities and a history of providing employee volunteers and supporting local science education \\ initiatives. These district partnerships quickly merged into one multi-district Partnership.
}

MISE's approach to improving science teaching has been systemic, addressing both policy and practice in the partner districts. MISE has helped its partners plan strategically, select highquality instructional resources, support teacher learning, and carry out instructional and curricular reforms. Working together, MISE and its partner districts have developed and implemented a shared vision of good science instruction based on national and state standards. This vision has been the basis for the design and delivery of professional development for teachers and administrators. Sustained by the Partnership since 1994, this professional development program has helped the partner districts make significant reforms in the teaching of science and mathematics. In 1993, MISE contracted with the Consortium for Policy Research in Education (CPRE) at the University of Pennsylvania to evaluate the effectiveness of its work with the four districts. CPRE has documented the activity and progress of the Partnership for a decade and has issued a series of reports on its impact.

In this report, we assess the Partnership's approach to professional development. Specifically, we address the following questions: 1 . How has the Partnership's professional development measured up against the emerging standards for professional development? 2. Has participation in Partnership professional development resulted in increased teacher content knowledge? 3. Has participation in Partnership professional development led to changes in instructional practice? 4. Has participation in Partnership professional development resulted in improved student achievement? 5. Has MISE's strategy strengthened district capacity to support the improvement of teaching? 6 . What lessons can be learned from the experience of MISE and the Partnership with professional development?

\section{Disciplines}

Curriculum and Instruction | Education Policy | Science and Mathematics Education | Teacher Education and Professional Development

\section{Comments}

View on the CPRE website. 


\title{
Getting It Right: The MISE Approach to Professional Development
}

\author{
Tom Corcoran \\ Siobhan McVay \\ Kate Riordan \\ CPRE Research Report Series \\ RR-055
}

December 2003

Consortium for Policy Research in Education

University of Pennsylvania

Graduate School of Education 



\section{Contents}

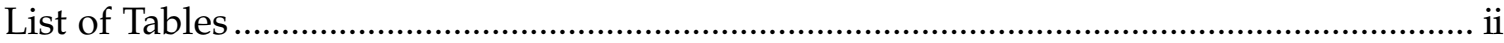

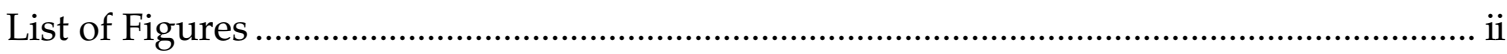

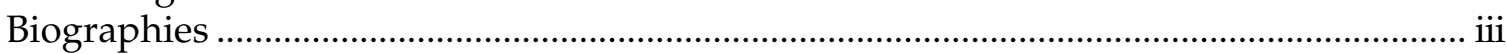

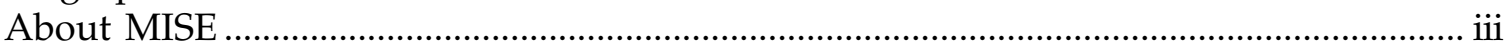

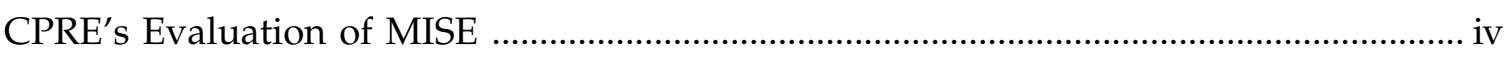

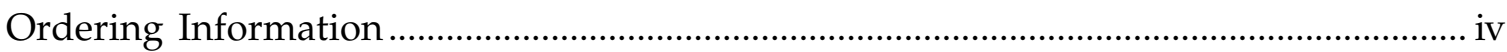

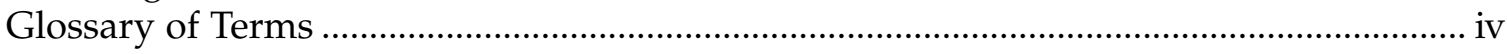

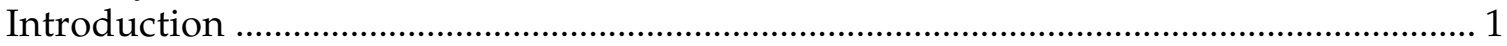

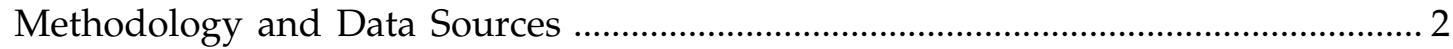

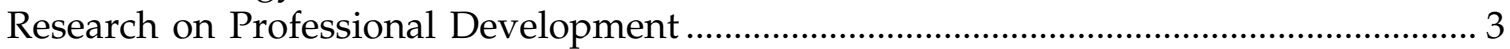

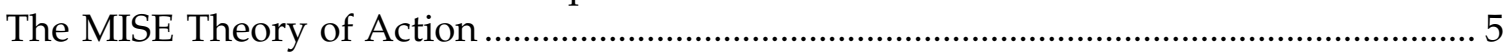

The Partnership's Professional Development .............................................................. 7

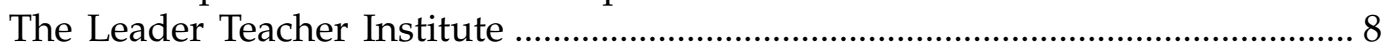

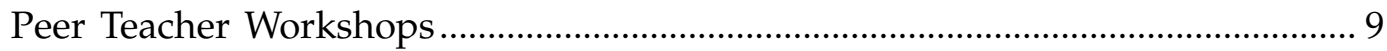

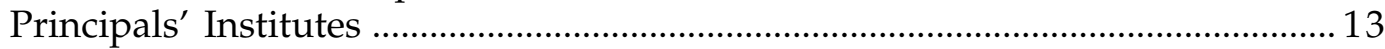

Did the Partnership's Professional Development Meet the Standards? .......................... 14

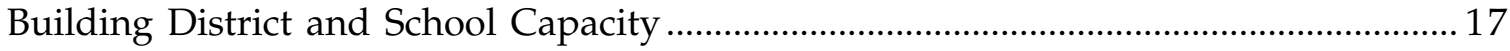

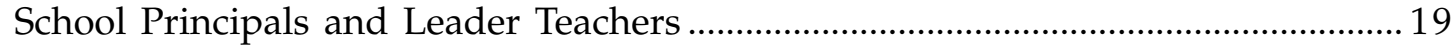

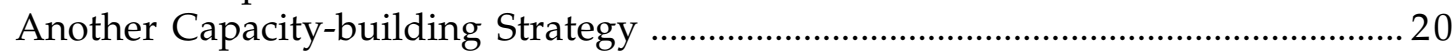

The Impact on Classroom Practice ……........................................................................... 21

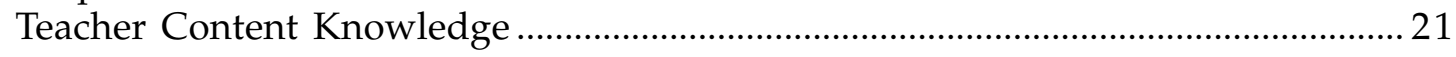

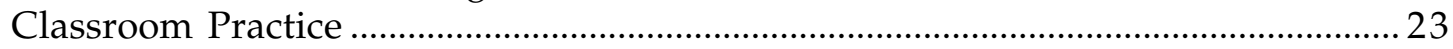

Summary of Impact on Practice ……...................................................................... 30

The Impact on Student Outcomes .................................................................................... 31

Summary: The Impact of Professional Development on Student Outcomes ............ 36

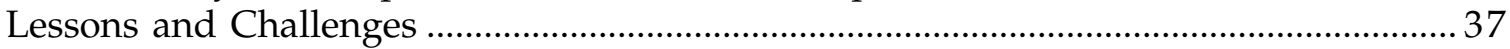

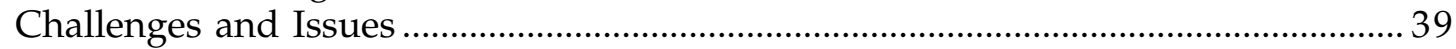

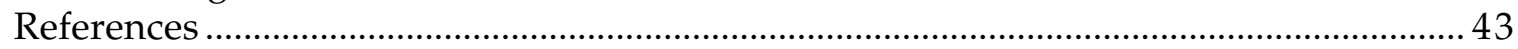

Appendix A. Annual Reports on CPRE's Evaluation of the Merck Institute for

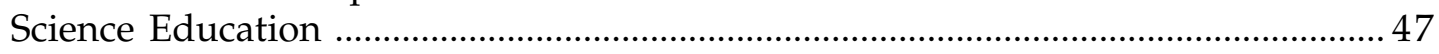

Appendix B. Additional Publications about the Merck Institute for Science 


\section{List of Tables}

Table 1. Enrollments and Grade Spans of the Partner Districts, 1993-1994 to 2000-2001 2

Table 2. Minority Enrollments and Poverty in the Partner Districts, 1993-1994 to 2000-2001 3

Table 3. Number of Peer Teacher Workshops and Enrollment, 1996 to 2002 10

Table 4. The Principals' Perspective of the Partnership, Results of the 2001 HRI Survey.

Table 5. Composition of Instructional Teams for Science Workshops, 1996 to 2001

Table 6. Mean Ratings for Teachers by Type of Professional Development, 1996-1997 to $1997-1998$

Table 7. Average Authentic Pedagogy Ratings of Science Lessons for Teachers with Varying Amounts of Professional Development 26

Table 8. Average Ratings for PTW Participants by Number of PTW Sessions

Attended and the Date of the Last Session 27

Table 9. Breadth and Depth of Saturation, Grades K-4 - New Jersey Districts ........... 34

Table 10. Breadth and Depth of Saturation, Grades K-3 - All Districts ........................ 35

Table 11. Zero-order Correlations Between Breadth and Depth of Professional Development and Science Assessment Results 36

\section{List of Figures}

Figure 1. Percentage of PTW Participants Who Found Selected Aspects of their Instructional Team's Delivery Very Effective or Extremely Effective, 1996 to 2000

Figure 2. Change in Leader Teachers' Knowledge, Pre- and Post-Mean LTI

Ratings

Figure 3. Impact of Professional Development on Teacher-reported Science

Teaching Practice

Figure 4. The Relationship Between Standards-based Teaching Practice and

Student Performance

Figure 5. Elementary School Proficiency Assessment 2001 General Education School

Mean 


\section{Biographies}

Tom Corcoran is co-director of the Consortium for Policy Research in Education (CPRE). Prior to joining CPRE, Corcoran served as the education policy advisor for New Jersey Governor James Florio, director of school improvement at Research for Better Schools, and director of evaluation and later chief-of-staff of the New Jersey Department of Education. His research interests include the use of research to inform policy and practice in public education, the efficacy of different approaches to professional development, the effectiveness of whole-school reform, the impact of changes in work environments on the productivity of teachers and students, and the factors affecting the effectiveness of scaling-up strategies.

Siobhan McVay was formerly a Research Assistant with CPRE at the University of Pennsylvania. After completing her B.S. in animal science and secondary teaching certification in the areas of chemistry and biology at Michigan State University, she worked as a classroom teacher for six years. McVay initially served as a junior high school science teacher in Chicago, and later as a chemistry teacher in the Rahway Public Schools (New Jersey). She also was affiliated with the Merck Institute for Science Education (MISE), specifically as a content area specialist instructional team member for Peer Teacher Workshops implemented through the MISE Partnership. Currently, McVay is pursuing a Master of Science in education degree with an emphasis in teaching, learning, and curriculum at the University of Pennsylvania.

Kate Riordan is a Research Specialist with CPRE at the University of Pennsylvania. She joined CPRE in 2001 after completing her doctoral degree in educational policy studies at Pennsylvania State University. Her Master's degree in Human Development and Family Studies is also from Pennsylvania State University. She is involved in two evaluation studies at CPRE - the evaluations of MISE and the America's Choice school design. Her research interests include school reform and other influences on children's school readiness and achievement throughout school.

\section{About MISE}

In 1993, Merck \& Co., Inc. began an endeavor to make a significant and visible commitment to improving science education by creating the Merck Institute for Science Education (MISE) and supported the new venture with a 10-year, \$20-million financial commitment. From its inception, MISE had two goals: to raise the interest, participation, and performance of public school students in science, and to demonstrate to other businesses that direct, focused involvement would hasten the improvement of science teaching and learning in the public schools. MISE initiated its work by forming partnerships with four public school districts - Linden, Rahway, and Readington Township in New Jersey, and North Penn in Pennsylvania - where Merck has major facilities. To learn more about MISE, visit www.mise.org. 


\section{CPRE's Evaluation of MISE}

CPRE, based at the University of Pennsylvania, was contracted by MISE in 1993 to document the implementation of the initiative and assess its impact on districts, schools, classrooms, and students. Throughout the evaluation, CPRE conducted interviews with teachers, instructional leaders, and district personnel; surveyed teachers; developed case studies of schools; and examined student achievement data in order to provide feedback on the progress of the MISE Partnership.

\section{Ordering Information}

Copies of this report are available free-of-charge. To obtain copies, write:

CPRE Publications

Graduate School of Education

University of Pennsylvania

3440 Market Street, Suite 560

Philadelphia, PA 19104-3325

\section{Glossary of Terms}

Merck Institute for Science Education Partnership - Created in 1993 by Merck \& Co., Inc., MISE began a 10-year commitment to the goal of raising student interest, participation, and performance in science. MISE formed partnerships with school districts in Linden, Rahway, and Readington Township in New Jersey, and North Penn in Pennsylvania.

Leader Teacher Institute (LTI) - Launched in 1995 to provide intensive professional development to a select group of teachers from each partner school over a three-year period. These teachers would then become the Leader Teachers within their schools.

Leader Teacher - Selected teachers who attended LTIs and worked with new teachers by orienting them to the new module-based science curriculum and provided instructional guidance and support.

Peer Teacher Workshops (PTWs) - Launched by MISE in 1996, PTWs provided professional development opportunities open to all K-8 teachers in an effort to engage more teachers in science reform. PTWs were open for voluntary enrollment and each was led by a team consisting of a combination of Leader Teachers, content specialists, instructional specialists, and classroom teachers.

Principals' Institutes - MISE offers Principals' Institutes to make sure that principals are remaining informed about, and support, inquiry-based instruction and other aspects of the reform process. 


\section{Introduction}

With an initial 10-year commitment from Merck \& Co., Inc. the Merck Institute for Science Education (MISE) was founded in 1993 to demonstrate that virtually all students could reach high levels of scientific literacy. Shortly thereafter, MISE formed partnerships with four public school districts - Linden, Rahway, and Readington Township in New Jersey, and North Penn in Pennsylvania - where Merck has major facilities and a history of providing employee volunteers and supporting local science education initiatives. These district partnerships quickly merged into one multi-district Partnership.

MISE's approach to improving science teaching has been systemic, addressing both policy and practice in the partner districts. MISE has helped its partners plan strategically, select highquality instructional resources, support teacher learning, and carry out instructional and curricular reforms. Working together, MISE and its partner districts have developed and implemented a shared vision of good science instruction based on national and state standards. This vision has been the basis for the design and delivery of professional development for teachers and administrators. Sustained by the Partnership since 1994, this professional development program has helped the partner districts make significant reforms in the teaching of science and mathematics. In 1993, MISE contracted with the Consortium for Policy Research in Education (CPRE) at the University of Pennsylvania to evaluate the effectiveness of its work with the four districts. CPRE has documented the activity and progress of the Partnership for a decade and has issued a series of reports on its impact. ${ }^{1}$

\footnotetext{
${ }^{1}$ See Appendix A and B for a complete listing
} of reports.
In this report, we assess the Partnership's approach to professional development. Specifically, we address the following questions:

1. How has the Partnership's professional development measured up against the emerging standards for professional development?

2. Has participation in Partnership professional development resulted in increased teacher content knowledge?

3. Has participation in Partnership professional development led to changes in instructional practice?

4. Has participation in Partnership professional development resulted in improved student achievement?

5. Has MISE's strategy strengthened district capacity to support the improvement of teaching?

6. What lessons can be learned from the experience of MISE and the Partnership with professional development?

The report is organized into eight sections. The introduction describes the research questions and data collection methods used by CPRE. In the second section, we summarize findings from recent studies of professional development, and describe the consensus standards of quality that have emerged in the past decade. MISE's theory of action and the professional development provided by the Partnership are described in section three. In section four, the latter is assessed against the consensus standards of quality. Section five presents an examination of the impact of the Partnership professional development strategy on the capacity of the partner districts and schools to support reforms in science education, and in the next two 
Table 1. Enrollments and Grade Spans of the Partner Districts, 1993-1994 to 2000-2001

\begin{tabular}{lcccc}
\hline Kistrict & $\begin{array}{c}\text { K-8 Enrollment } \\
\text { 1993-1994 }\end{array}$ & $\begin{array}{c}\text { K-8 Enrollment } \\
\text { 2000-2001 }\end{array}$ & Grade Span & $\begin{array}{c}\text { \# of Schools, } \\
\text { Grades K-8 } \\
\text { 2000-2001 }\end{array}$ \\
\hline Linden & 3,405 & 4,204 & K-12 & 10 \\
North Penn & $7,759 *$ & 10,534 & K-12 & 14 \\
Rahway & 2,229 & 2,747 & K-12 & 5 \\
Readington & 1,473 & 2,113 & K-8 & 4 \\
\hline
\end{tabular}

* This figure represents grades K-7 as eighth graders attended the high school.

sections, we look at the Partnership's impact on teaching and learning. We conclude by examining some lessons to be learned from the experience of MISE and the Partnership, and consider the issues that it raises.

\section{Methodology and Data Sources}

The data for this report come from a longitudinal evaluation of a business-led partnership seeking to improve the quality of science instruction in grades K-8 in four school districts. Two of the districts served small urban communities; one was suburban, and one was a rapidly developing rural area. In Table 1, enrollment data are presented for the 1993-1994 and 2000-2001 school years, representing the beginning and near the end of the study period.

Table 2 displays data on minority enrollment and the percentage of students eligible for free and reduced-price lunch. There is considerable variation among the partner districts, which range from blue-collar towns in New Jersey to rural and suburban enclaves. The data show increases in minority enrollments and the numbers of students living in poverty in both Linden and Rahway.

Thirty-four schools served grades K-8 in the four districts. The average school population of the schools was 551 students. The largest school had 1,380 students and the smallest had 284 students. Eighty percent were elementary schools and $20 \%$ were middle schools.

For a decade, CPRE has documented the work of MISE and the collaborative it formed with its four partner districts, known as the Partnership. The CPRE evaluation team has examined the evolution and efficacy of the theory of action guiding this work, focusing on the quality and impact of the professional development and technical assistance provided by MISE and its partners. We have looked for evidence of impact on district and school policy, school culture and organization, curriculum and classroom practice, and student outcomes. Between 1996 and 2002, the Partnership was funded in part by a Local Systemic Reform (LSC) grant from the National Science Foundation (NSF), and CPRE cooperated with Horizon Research, Inc. (HRI), the national evaluator of the LSC program. HRI provided some of the interview protocols, an observation protocol, and a teacher survey. HRI also drew annual samples of teachers to be observed. However, with support from MISE, CPRE broadened the HRI data collection activities to survey all K-8 teachers and administrators in the four districts and to conduct additional observations and interviews. As a consequence, each year CPRE staff conducted interviews with district and 
Table 2. Minority Enrollments and Poverty in the Partner Districts, 1993-1994 to 2000-2001

\begin{tabular}{|c|c|c|c|c|}
\hline District & $\begin{array}{c}\text { \% Minority } \\
1993-1994\end{array}$ & $\begin{array}{c}\text { \% Minority } \\
2000-2001\end{array}$ & $\begin{array}{l}\text { \% Eligible for Free } \\
\text { and Reduced- } \\
\text { price Lunch } \\
1993-1994\end{array}$ & $\begin{array}{l}\text { \% Eligible for Free } \\
\text { and Reduced- } \\
\text { price Lunch } \\
2000-2001\end{array}$ \\
\hline Linden & 46.6 & 61.0 & 30.0 & 43.5 \\
\hline North Penn & 12.7 & 18.3 & NA & 10.5 \\
\hline Rahway & 47.4 & 65.0 & 22.0 & 30.0 \\
\hline Readington & 3.5 & 5.2 & NA & 1.2 \\
\hline
\end{tabular}

school staff, professional development leaders, and MISE staff, observed classroom teaching and professional development activities, and administered the HRI surveys. On average, 600 to 700 teachers completed the annual HRI surveys and response rates ranged from $70 \%$ to $85 \%$. Between 20 to 100 classroom observations and 50 to 100 interviews were conducted each year. A set of case study schools was visited every two years.

CPRE has produced annual reports on the work of MISE and the Partnership. ${ }^{2}$ Also, CPRE issued a series of reports on the long-term impact of MISE and the Partnership including this report on professional development. ${ }^{3}$

\section{Research on Professional Development}

Policymakers and school reformers are calling for improvements in the quality of teaching, and there is broad agreement that this requires more and better professional development for teachers. Linda Darling-Hammond (1997) of the National Commission on Teaching and America's Future has

${ }^{2}$ The eight annual reports are listed in Appendix A.

${ }^{3}$ These longitudinal reports are listed in Appendix B. recommended improving both the quality and quantity of professional development in order to promote the continuous improvement of teaching. Elmore (2002) argues that both the pedagogical skill and content knowledge of professional teachers must be enhanced to produce the sustained gains in student learning envisioned by the advocates of standards. Yet, in spite of these and similar recommendations from many other professional organizations and reform leaders, as well as the pressures emanating from higher-stakes accountability systems, at the beginning of the $21^{\text {st }}$ century, most teachers in the United States experience limited opportunities to improve their knowledge and skill (Desimone, Porter, Garet, Suk Yoon, \& Birman, 2002). And these professional development opportunities usually are fragmented, poorly aligned with the curricula teachers teach, and inadequate to meet their needs for deeper knowledge of subject matter and understanding of pedagogy (Cohen \& Hill, 2001; Corcoran \& McDiarmid, 2000; Desimone et al., 2002; Elmore, 2002; Loucks-Horsley, Love, Stiles, Mundry, \& Hewson, 1998; Supovitz, 2003). For too many teachers, professional development opportunities consist of occasional "in-service programs" of limited duration - typically half-day or full-day workshops in which they are exposed to faddish teaching strategies or new theories about teaching and learning. Often, the content of these programs is not connected to their daily work, and 
there is little or no follow-up support to help them use the knowledge or skills they have acquired.

In recent years, researchers have begun to examine what works in professional development. Supovitz, Mayer, and Kahle (2000) studied the effects of intensive, standards-based professional development on teachers of science in Ohio and found that teachers became more positive about instructional reforms and more likely to use inquirycentered pedagogy. Cohen and Hill (2001) studied mathematics teachers who participated in the intensive curriculum-based professional development offered by the California Subject-matter Network in the 1990s, comparing the changes made in their practice with those made by teachers who received more conventional professional development in mathematics. They found that teachers who participated in the former were much more likely to make changes in their practice, and that these changes were associated with gains in student performance. They concluded that providing teachers with extended content-specific opportunities combined with follow-up support produced results.

These findings are consistent with those from other studies of the California Subject-matter Network (Pennell \& Firestone, 1996; Wilson, 2003), research on the reforms in literacy and mathematics teaching carried out in District \#2 (Elmore \& Burney, 1997), evaluations of the National Writing Project (St. John \& Stokes, 2003), and secondary analysis of data from NSF's LSC projects (Supovitz \& Turner, 2000). Moreover, studies of comprehensive school reform programs like Success for All and America's Choice (Haslam \& Seremet, 2001; Supovitz \& Taylor, 2003) and the national Eisenhower program

(Desimone et. al., 2002; Birman, Desimone, Garet, \& Porter, 2000) have yielded similar results. The general conclusion is that extended opportunities to engage in professional development that is aligned with the curriculum to be taught, and accompanied with onsite follow-up support, can produce significant changes in classroom practice and benefits for students.

These findings are consistent with the experiences of those who design and deliver professional development, and, as a consequence, a consensus has emerged about what constitutes effective professional development. Researchers and designers of professional development have reached broad agreement on a set of principles or standards that they believe characterize effective professional development programs; that is, programs leading to changes in teaching practices.

According to this "consensus" view, high-quality professional development programs:

- Are grounded in research and clinical knowledge of teaching and learning;

- Are aligned with the curriculum and assessments in use in the setting;

- Are focused on student learning in a particular context;

- Model good practice throughout the program, modeling methods of constructivist teaching or inquirybased methods;

- Are active learning opportunities for teachers including practice, feedback, and reflection;

- Are transparent about the limitations of the evidence supporting the desired practice; 
- Are intensive and include follow-up and on-site support for teachers;

- Are sustained over time, allowing teachers to integrate new knowledge and strategies into their practice and to reflect on the experience;

- Focus on building teachers' pedagogical skills and content knowledge in their subject areas;

- Utilize the expertise of teachers in schools and districts, cultivate leaders, and involve teachers in planning;

- Provide structures that facilitate collaboration among teachers both within and across schools; and

- Respect teachers as professional, adult lifelong learners.

(Cohen \& Hill, 2001; Corcoran, 1995; Desimone et al., 2002; Elmore, 2002; Lieberman \& Wood, 2002; LoucksHorsley et al., 2003; National Research Council, 1996; National Staff Development Council, 2001; Supovitz, 2003)

These 12 principles are consistent with the standards for professional development adopted by the National Staff Development Council (2001; Killion, Munger, Roy, \& McMullen, 2003), the American Federation of Teachers (1999), and the National Institute for Science Education (LoucksHorsley, Stiles, \& Hewson, 1996). They reflect the findings from well-designed research studies as well as the clinical expertise of those who have designed and delivered professional development. While designing professional development according to these principles will not guarantee success, it can increase the likelihood that participants will use what they are learning to change their practice. We will use these principles as a framework for assessing the quality of the professional development provided by MISE.

\section{The MISE Theory of Action}

Guided by a board of advisors that included representatives of the National Science Resources Center, the National Science Teachers Association, the National Academy of Sciences, and leading scientists and science educators, and led by a respected science educator, MISE developed partnerships with educators in four districts in New Jersey and Pennsylvania aimed at reforming science teaching in the elementary and middle grades. ${ }^{4}$ MISE sought a dramatic transformation from textbook-based, memorization-oriented instruction to guided inquiry in which students actively engaged in science investigations based on structured curriculum units such as those developed by FOSS (Full Option Science System) and STC (Science and Technology for Children). While some reformers subscribe to a more radical view of inquiry in which students determine the topics and questions to be explored and conduct their own inquiries, MISE advocated a more practical vision suited to $\mathrm{K}-8$ teachers. While supporting student inquiry, the MISE strategy used tested standards-based curriculum units as the backbone of the science curriculum. These units framed classroom inquiry and ensured that all students learned key concepts. MISE refers to this strategy as inquiry-centered science teaching.

MISE sought to make inquiry an integral and regular part of the experience of all students at all grade levels. In

${ }^{4}$ A complete account of the story of MISE's partnership with the four districts is found in Corcoran (2003). 
inquiry-centered classrooms, students were expected to conduct scientific investigations under the guidance of their teachers; learn to collect, analyze, and interpret data; and explain their observations and results. This vision of high-quality science education required moving elementary science teachers away from their dependence on textbooks and this posed significant challenges for many teachers. As in most school districts across the United States, elementary science in the four partner districts was taught by generalist teachers whose science backgrounds were limited - typically consisting of only one or two basic college courses. In fact, making sure science was taught at all in the elementary grades was a challenge when MISE began its work. There were no state assessments in science in 1993, and the reputations of elementary schools and their relationships with the state departments in New Jersey and Pennsylvania depended largely on the performance of students in reading, writing, and mathematics, not science. Thus, in many elementary classrooms, science, when it was taught, was often merely an extension of the reading program.

To put their vision of science teaching into practice, MISE staff helped the four districts review and select commercially available science modules that could support student inquiry and cover the key concepts identified in state and national standards. To implement this new curriculum and engage in inquirycentered teaching, teachers needed professional development, but other changes were needed as well. As a consequence, MISE took a systemic approach in its work with the partner districts, and its theory of action included the following 10 components:

- Persuading districts to make the improvement of science teaching a priority, and to engage in serious planning to address it;
- Developing a leadership team in the district that shared a common vision of science teaching grounded in inquiry and consistent with state and national standards;

- Helping districts develop new curriculum frameworks for science, select appropriate instructional materials, and develop systems for the management of the materials to ensure they could be used effectively;

- $\quad$ Providing access to content-based professional development for teachers over an extended period of time and on-site follow-up support to enable teachers to use the curriculum materials effectively;

- Building district capacity to plan and deliver this professional development;

- $\quad$ Supporting the use of assessments that were consistent with the vision of good teaching, including formative assessments, end-of-unit assessments, and district-wide performance assessments and examinations;

- Developing leadership cadres who could carry out this work;

- Developing professional cultures for the districts and schools that would promote and support continuous improvement of science teaching and develop teacher expertise;

- Aligning district policies for curriculum, professional development, resource allocation, and teacher evaluation with the vision of reformed practice and the strategies for improvement; and

- $\quad$ Promoting supportive state policies. 
The leaders of MISE believed that a comprehensive approach was needed to stimulate, support, and sustain the inquiry-centered classroom practice they sought. New curriculum materials and professional development were essential, but school and district policies governing curriculum, assessment, professional development, resource allocation, personnel evaluation, and accountability also had to be aligned with the vision of high-quality science teaching if the reforms were to take root in classrooms and be sustained.

\section{The Partnership's Professional Development}

Professional development is the central driver in the MISE theory of action. MISE and the Partnership have designed professional development with four key objectives in mind: effective implementation of newly adopted curriculum modules in science, the use of inquiry as a primary instructional strategy in science teaching, the use of performance assessment as a source of formative feedback for instruction, and the development of teacher leadership. Over time, the Partnership has pursued these objectives through a variety of complementary professional development activities. In the first two years of MISE's partnerships with the four districts, priority was placed on the review and selection of new standardsbased science curriculum modules for use in grades K-8. Although MISE supported related district professional development programs, it quickly became apparent that these local efforts were not robust enough to stimulate and support the changes in practice that MISE envisioned.

It was at that point that MISE and the four districts formed the Partnership and adopted a common professional development strategy. The Partnership began its professional development work in 1994 with the selection of teams of three-to-four "Leader Teachers" from each school serving grades K-8. These teams attended three-week summer institutes and five-to-seven follow-up sessions each year for three consecutive years. Known as the Leader Teacher Institute (LTI), these experiences were not only intended to enhance participants' knowledge of science content and their skills in inquiry-centered teaching, but to prepare them to be leaders in their schools and districts. The LTI was designed and delivered by instructional teams that included specialists in science, pedagogy, and leadership. The participating teacher teams were expected to promote and support the implementation of the new curricular units, the use of inquiry-centered instruction, and the introduction of performance assessment.

In 1996, a complementary strategy was introduced. With the support of an LSC grant from NSF, the Partnership extended access to professional development in science and mathematics to all elementary and middle school teachers through multi-day summer programs known as Peer Teacher Workshops (PTWs). Typically, a PTW focused on a single multi-week science unit, addressing curriculum content, classroom and unit management, pedagogy, assessment, and responses to common student misunderstandings and learning problems. The selection of PTWs offered each summer was determined by the needs and interests of teachers and the adoption of new science units by the four districts. PTWs were provided in mathematics, technology, and assessment as well as science. Teachers, including the Leader Teachers, could attend multiple sessions during the summer, and they could participate in PTWs year after year. The PTWs were planned and led by instructional teams composed of district staff, accomplished teachers, 
MISE staff, and external consultants who helped to ensure quality of the design and implementation. In the first two years, the PTWs were jointly planned and were offered in central locations for teachers from all four districts. Based on CPRE findings that this created a barrier to participation for some teachers, the Partnership shifted to a district-based strategy for delivering the PTWs but the four districts continued to collaborate on planning, and teachers crossed district lines to attend the programs.

Careful attention to the design of learning experiences for adults and the continuous improvement of these designs were hallmarks of the PTW program. Each spring, MISE held a two-day design retreat for the instructional teams responsible for designing and delivering the PTWs in all four districts. Team members were introduced to the expectations and standards of the Partnership's curriculum-based approach to professional development, provided with assistance as they designed the next round of summer institutes, and introduced to a professional learning community focused on the development and sharing of knowledge about effective strategies for engaging teachers and supporting their learning. This strategy of assisted design informed by experience contributed significantly to the quality of the PTWs.

A third strategy focused on principals. In the initial years, MISE provided professional development for the principals around the science standards, the use of inquiry, and how to work with the Leader Teachers to improve practice. In later years, the Partnership offered a series of institutes for principals that focused on what to look for in the classroom, revision of observation instruments, and how to assist teachers with the improvement of their practice.
The provision of on-site follow-up support, the fourth strategy, was an essential feature of both the LTI and PTW programs. The MISE and district supervisory staffs provided support for the Leader Teachers. The Partnership took a four-fold approach to follow-up for the PTWs: supporting formal meetings of PTW participants during the school year, preparing district science supervisors to support reformed classroom practice, organizing on-site support from the Leader Teachers, and preparing principals to know what to look for in classrooms.

Finally, the Partnership supported teacher networks. Teachers were recruited to work on curriculum frameworks, performance assessments for use in the science modules, and the administration of performance assessments in several grades. This work was typically done by study groups of teachers who worked within, and across, the four districts to develop these new tools for the improvement of instruction. Supported by MISE staff and other consultants, these study groups and networks provided rich professional development for many teachers in the four districts.

Below, we take a more detailed look at the first three of these strategies.

\section{The Leader Teacher Institute}

The LTI was designed to prepare teams of Leader Teachers to support the spread of reformed science teaching in their schools. The objectives were to deepen their knowledge of science, enhance their skills in inquiry-centered pedagogy, and prepare them to lead the improvement of science teaching in their schools and districts. The Leader Teachers were expected to:

- Embrace and spread the use of inquiry-centered teaching; 
- Increase their knowledge of science;

- Implement inquiry-centered instruction in their classrooms;

- Develop the "habits of mind" of science learners;

- Design and use assessments that informed instruction;

- Integrate science, mathematics, and technology with other disciplines;

- Create classrooms in which all students were fully engaged;

- Model and demonstrate these practices for their colleagues;

- Assume responsibility for their own continuing professional development; and

- Provide leadership within their schools and communities.

For several years, the LTI was the Partnership's core activity. It raised the visibility of science in the four districts and spread the vision of inquiry-centered science instruction. It helped transform four district partnerships with MISE into a single collaborative effort the Partnership. It stimulated schoolwide initiatives to improve science teaching, and it altered the roles of MISE staff as they became change agents and providers of technical assistance.

\section{Peer Teacher Workshops}

In its third year, the Partnership received a major grant from NSF's LSC program. The primary objective was to provide, over a five-year period, 100 hours of high-quality professional development in science and mathematics to at least $80 \%$ of the nearly $800 \mathrm{~K}-8$ teachers who taught these subjects in the four partner districts. The NSF grant enabled the Partnership to move beyond the preparation of Leader Teachers and directly engage all K-8 teachers in the four districts.

Three-to-four-day summer workshops combined with follow-up sessions during the school year were first offered in the summer of 1996. Participation was voluntary but encouraged by the districts and all teachers were invited to attend. Principals, Leader Teachers, science supervisors, and others recruited participants. Initially, the workshops focused on the science modules adopted by the districts and they were organized by grade-level clusters.

In the first summer of the PTWs, 169 regular classroom and special education teachers (87 in New Jersey and 82 in Pennsylvania) participated in one of three theme-based sessions - Observing and Measuring in the Real World (grades pre-K-2), About Matter (grades 3-5), and Environmental Science: Sustaining the Earth (grades 5-8). Each summer since, PTWs have been offered to teachers in Partnership schools. The PTWs have been expanded over time to cover mathematics, technology, and assessment as well as additional science modules. The PTWs broadened the scope of the Partnership's work, engaging more teachers in the reform of science and mathematics education.

Participation in the PTWs grew steadily during the first few years of the LSC project. Table 3 shows the numbers of teachers participating each summer from 1996 to 2002. From 1996 to 2002, more than $80 \%$ of the eligible teachers attended two or more of the summer workshops, and over $60 \%$ attended three or more. Each PTW involved 30 hours of professional development during the summer and follow-up sessions during the school year, representing a significant investment of 
Table 3. Number of Peer Teacher Workshops and Enrollment, 1996 to 2002

\begin{tabular}{lcccccc}
\hline Year & $\begin{array}{c}\text { Number of } \\
\text { PTWs }\end{array}$ & $\begin{array}{c}\text { Math } \\
\text { PTWs }\end{array}$ & $\begin{array}{c}\text { Math and } \\
\text { Science } \\
\text { PTWs }\end{array}$ & $\begin{array}{c}\text { Science } \\
\text { PTWs }\end{array}$ & $\begin{array}{c}\text { PTW } \\
\text { Enrollment }\end{array}$ & \# of Individuals \\
\hline Summer 1996 & 6 & 0 & 0 & 6 & 169 & 169 \\
Summer 1997 & 8 & 2 & 0 & 6 & 195 & 195 \\
Summer 1998 & 22 & 8 & 1 & 13 & 506 & 287 \\
Summer 1999 & 36 & 9 & 1 & 26 & 525 & 386 \\
Summer 2000 & 32 & 9 & 2 & 21 & 667 & 490 \\
Summer 2001 & 37 & 12 & 1 & 24 & 536 & 394 \\
Summer 2002 & 25 & 0 & 0 & 25 & 581 & 361 \\
Total & 166 & 40 & 5 & 121 & 3,179 & 2,282 \\
\hline
\end{tabular}

teacher time in professional development.

Instructional Teams. The PTWs were designed by teams of three or four workshop instructors including a science or mathematics content specialist, an experienced professional developer, and one or two accomplished classroom teachers. The inclusion of accomplished teachers from the partner districts was a deliberate effort to ground the PTWs in the realities of classroom practice in the participants' context. It also was intended to build the capacity of the districts by developing cadres of teachers who could confidently and expertly design and lead professional development and serve as peer mentors and coaches. The teams were brought to a two-and-a-half-day retreat in Princeton, NJ each spring. Designed by MISE staff, the retreat was intended to provide the instructional team members with a shared vision of high-quality professional development, time to design their PTW, and assistance with design. The objectives for the retreats were to:

- Establish good working relationships among instructional team members;

- Make the roles of the team members explicit;
- Assess the strengths and needs of individual team members;

- Review the elements of effective professional development and apply them in designing the content and format of PTWs;

- Establish expectations and guidelines for designing workshop sessions, ordering workshop supplies, scheduling team planning meetings, producing workshop materials, documenting workshop planning and facilitation, and tracking participant attendance; and

- Begin the planning of the PTWs for the summer.

At the retreats, district and MISE staff demonstrated good professional development. Participants engaged in hands-on investigations and tried out strategies for reviewing student work. They reviewed the standards for professional development and discussed situations that might arise in the course of a PTW. Ample time was always allowed for teams to meet to plan their summer workshops.

The instructional teams met throughout the spring to complete their designs and assemble materials; MISE staff met 
with them to assist as needed and to review the science content with the team members.

From the second year on, the instructional teams had the designs, materials, and evaluation data from the previous years' PTWs available to guide their work. As a result, the designs were elaborated and improved over time. In interviews with CPRE evaluators, the instructional team members gave glowing accounts of the retreats. They reported that they had learned a great deal about science and how to teach it, as well as acquiring knowledge about how to design and guide learning experiences for adults.

During the PTWs, the instructional teams modeled the pedagogy they were trying to get teachers to use, and participants conducted investigations, worked in cooperative learning groups, analyzed instructional activities against standards, and reflected on their current practices and what they were learning. Teachers participated in guided inquiry themselves, explored the science content of the modules, observed demonstrations to illustrate key concepts, designed challenging instructional activities for their students, considered alternative ways of assessing student understanding, and discussed student engagement, logistics, and classroom organization.

\section{The Quality of the Instructional}

Teams. Did the PTW participants think that the instructional teams possessed the necessary knowledge and skills? Did they find them helpful? Participants completed evaluation surveys at the end of each PTW. Year after year, the vast majority reported being highly satisfied with the PTWs, and their responses to questions about the PTW instructional teams were overwhelmingly favorable. Teachers gave their highest ratings to the instructional teams' knowledge of science/mathematics content and their ability to model inquiry-centered instruction.

Figure 1 presents aggregated participant responses to some of the key questions about the instructional team that led their sessions. Ninety-six percent of the participants said the instructional team's knowledge of science or mathematics instruction was either very or extremely effective. In addition, almost $90 \%$ of the participants felt that the

\section{Figure 1. Percentage of PTW Participants Who Found Selected Aspects of their Instructional Team's Delivery Very Effective or Extremely Effective, 1996 to 2000}

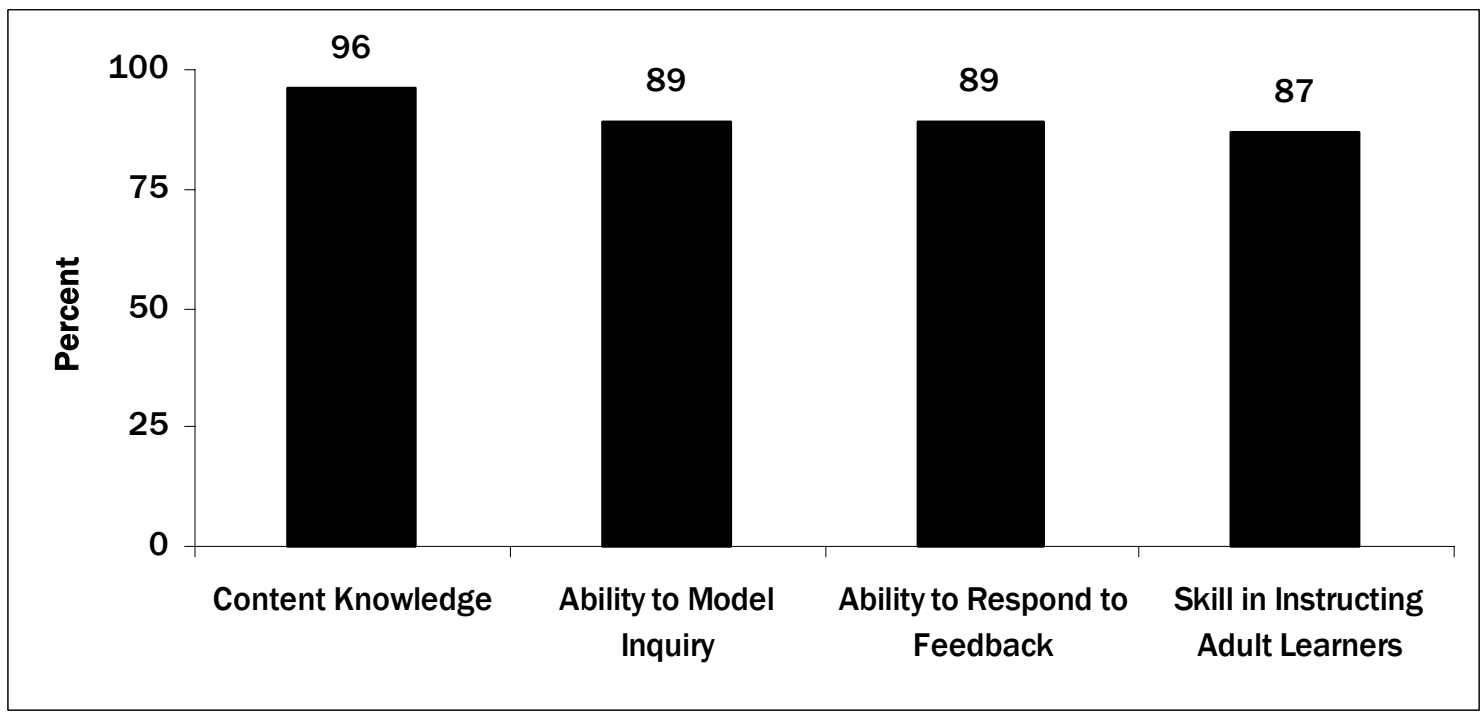


instructional teams were very or extremely effective in their ability to model inquiry-centered instruction, in their ability to respond to participants' questions and feedback, and in their skill in instructing adult learners.

Each year, some of the instructional team members were conducting workshops for the first time, and despite MISE's efforts to provide them with guidance and support (through the design retreat and the inclusion of content experts on the instructional teams), there was always some unevenness in the delivery of PTWs. However, the overall impression of CPRE evaluators was that only a modicum of quality was sacrificed by recruiting accomplished teachers to serve on the teams, and the strategy helped build greater district capacity in the long run.

Based on the sessions observed by CPRE staff and follow-up interviews with participants, most PTW leaders were perceived by participants to be knowledgeable and skilled. Effective instructional team members stimulated participants' interest in science and helped them master the content of the curriculum. A typical participant commented:

This has been perhaps one of the best workshops I have attended because of the facilitator's preparedness, style, and knowledge of the classroom and program. I feel much better prepared to implement the program, to assess it, and to share my knowledge and techniques with my peers.

Another respondent said:

The instructional team did a wonderful job. This is the second time that I've been in a workshop with [instructor]. She makes us all feel that we are physicists. Certainly, all aspects [of the workshop] can be used, but I found the science content and inquiry-centered instructional techniques to be most helpful for me. Being able to revisit content in this new light helped to refresh my memory and made clearer for me the great value of using inquirycentered methods.

When asked what they intended to use in their classrooms, participating teachers mentioned the inquiry approach, better questioning techniques, specific content knowledge, and new assessment tools. These were the outcomes the Partnership was seeking. While intentions do not always predict changes in practice, the data from follow-up surveys and interviews suggest that most of the participants put their newly acquired knowledge and skills to use in their classrooms.

CPRE evaluators also interviewed instructional team teachers several times in order to obtain their assessment of the PTW experience. Did they feel prepared to design and lead a workshop? Did they receive the support they needed? Did they feel respected by other team members and the participants? Did they believe that the workshops were changing classroom practice? The answers to these and related questions were universally positive. The strategies of focusing on curriculum units, co-constructing the designs, and using accomplished practitioners to lead them were perceived to be the keys to their success. The teachers reported that they were clear about the skills they brought to the instructional team and that they were satisfied with their role on the team. As one teacher remarked:

I was part of the basic decision-making process. We were given a basic framework, but we were allowed to shape it from the ground up within our discipline, including what our themes would be and what activities we might use. We all brought to the table what we had or could find. 
All of the teachers said that they were initially uncomfortable as instructors but quickly grew into the role. They all felt that the experience had deepened their understanding of science and affected their classroom practice, and many indicated that it had empowered them and altered their aspirations as professionals and the opportunities for influence within their districts.

\section{Principals' Institutes}

The implementation of instructional reforms requires support from school principals. In study after study, researchers examining the factors affecting the implementation of reforms have confirmed this finding (Elmore, 2000; Newmann \& Associates, 1996; Spillane, Halverson, \& Diamond, 2001). Strong principals provide their staffs with vision and focus, creating coherence within their schools. They support the efforts of teachers to improve their practice, building strong professional communities that focus on results and promote collaboration, and providing assistance to teachers who need it. They allocate resources, including time to support the instructional priorities of their schools, and buffer their staffs from distractions. In sum, principals play a critical role in improving instruction.

Although MISE recognized the important role played by principals, it focused on strengthening the science curriculum, developing Leader Teachers, and providing professional development for teachers. Initially, MISE introduced principals to the science standards and their vision of reformed practice, and worked with them on the effective use of the Leader Teachers in their schools. But during the middle years of the Partnership, 1997 to 2000, MISE focused more on the engagement of central office personnel and teachers than it did on principals. The assumptions were that the superintendents, central office staff, and Leader Teachers would win over the principals, gain their support for the Partnership's work, and provide them with whatever preparation they needed to support reforms in science teaching.

Feedback from the field soon indicated that the principals needed more preparation to support the reforms in science teaching. The CPRE evaluation of the work of the Leader Teachers revealed that some did not receive support from their principals. Teachers who attended the PTWs told CPRE evaluators that the priorities and attitudes of their principals determined the degree to which they could use inquiry methods in science. Also, teachers responding to the HRI survey reported considerable variation in the support being provided by their principals. District leaders also expressed concern that turnover meant that there were many new principals who had only vague notions of the instructional vision of MISE and the Partnership.

The results of the HRI administrator surveys provided a somewhat more positive picture than the other data sources perhaps because the principals felt some pressure to indicate that they were involved. Nevertheless, about a quarter of the principals reported something less than active involvement in the Partnership's work on the 2001 survey (see Table 4).

As a consequence, during 2000-2001, MISE convened a representative group of principals from the four districts to discuss what should be done to prepare principals to be effective instructional leaders in science. The result was a professional development program for principals that focused on what to look for in science classrooms, distributed leadership and how to make effective use of accomplished teachers, and supporting teacher learning on the job. The first two-day institute in June 2001 was attended by 41 principals and some central office staff. Three other sessions 


\section{Table 4. The Principals' Perspective of the Partnership, Results of the 2001 HRI Survey}

\begin{tabular}{lccc}
\hline Item & Not at all & $\begin{array}{l}\text { Responses } \\
\text { Somewhat }\end{array}$ & To a great extent \\
\hline $\begin{array}{l}\text { How familiar are you } \\
\text { with the LSC project? }\end{array}$ & $6.5 \%$ & $9.7 \%$ & $83.9 \%$ \\
$\begin{array}{l}\text { To what extent have } \\
\text { you been involved? }\end{array}$ & $13.0 \%$ & $9.7 \%$ & $77.4 \%$ \\
\hline
\end{tabular}

followed, and were also well attended. These Partnership Principals' Institutes were planned by a committee of principals from the four districts and MISE.

Principals' responses to the institutes were overwhelmingly positive. Followup interviews revealed a demand for more experiences focused on instructional practice and an appreciation of opportunities to interact with peers from other districts. By bringing the principals together, the Partnership helped develop a community of practitioners who could learn from one another. Participation in the institutes was higher than expected, and the principals requested additional sessions. One outgrowth of these sessions was the revision of local teacher observation instruments to make them more consistent with the Partnership's vision of good instruction.

\section{Did the Partnership's Professional Development Meet the Standards?}

Did the learning opportunities for teachers designed by the Partnership meet the consensus standards for highquality professional development that we described earlier? Overall, CPRE's assessment is that the Partnership's model of active and deep engagement with curriculum content and pedagogy combined with follow-up during the school year and in the workplace was consistent with the consensus view of quality and with the standards adopted by the National Staff Development Council (2001; Killion et al., 2003), the American Federation of Teachers (1999), and the National Institute for Science Education (Loucks-Horsley, Stiles, \& Hewson, 1996). The MISE staff understood the standards and applied them, and they were committed to improving the quality of their work. They actively sought and used feedback on their processes and designs from participants, district staff, and CPRE evaluators. A cyclical process of design, implementation, feedback, and redesign was central to their work. Here, we take a look at how well the Partnership's work measured up to the 12 standards presented earlier.

The first standard states that professional development should be solidly grounded in research and clinical knowledge of teaching and learning. The science content of the LTI and PTW programs was based on the national and state science education standards, which are the best available syntheses of research and clinical knowledge in science education (National Research Council, 1996; Olson \& Loucks-Horsley, 2000). These programs focused on key concepts in the physical, biological, and earth sciences included in the K-8 curriculum and on the use of inquiry, which is treated as an essential aspect of science content in the national standards. The inclusion of expert teachers, district supervisors, and pedagogical experts on the LTI and PTW instructional teams 
ensured a solid grounding in clinical knowledge of teaching and learning.

The second standard states that professional development should be aligned with the curriculum that teachers are expected to teach, and the PTWs certainly were well aligned. Approximately two-thirds of the PTWs were designed to help teachers implement specific science curriculum modules. The remaining workshops focused on writing in science, mathematics, integrating technology, and student assessment.

The third standard recommends focusing on student learning in a particular context. Both the LTI and PTW experiences focused heavily on developing teachers' understanding of the core science concepts covered in the local curricula and on student understanding of them. The PTWs were designed around specific curricular units being offered to particular groups of students. Considerable attention was directed to how students might respond to these activities and what concepts or procedures they might misunderstand, how to engage students in inquiry, and how to assess student understanding. Since the instructional teams included teachers who had taught the units to similar groups of students, they were able to help participants make these connections to their classrooms. The follow-up sessions sometimes involved looking at student work and almost always involved discussion of real teaching and learning problems encountered in Partnership classrooms.

The fourth standard recommends modeling of good practice. MISE staff certainly encouraged this in the design retreats. They modeled good practice themselves, and helped others do so by coaching them. Both LTI leaders and PTW instructional team members modeled the pedagogy they were trying to get teachers to use. Participants con- ducted investigations, worked in cooperative learning groups, received feedback from instructors and other teachers about their instruction, and reflected on what they were learning. Leader Teachers were often asked to model the use of inquiry for others who were having difficulty implementing it in their classes. MISE professional development was designed to enable teachers to demonstrate and share their knowledge so it could spread throughout their schools.

The fifth standard emphasizes the importance of active learning opportunities for teachers including practice, feedback, and reflection. Both the LTI and the PTWs provided low-risk, collaborative environments and structured opportunities for practice, peer feedback, and time for reflection. Participating teachers conducted experiments, observed and critiqued demonstrations, planned and carried out inquiry-based activities, and reflected on their experiences. The follow-up sessions provided rich opportunities for reflection as teachers could share accounts of their efforts to use the modules and strategies, discuss their students' responses and the problems they encountered, and examine student work.

The sixth standard - the transparency of the limitations of the evidence supporting the desired practice - will be discussed at the end of this section.

The seventh and eighth standards address the intensity, duration, and persistence of the experiences and the presence of on-site support. The LTI and PTWs clearly offered teachers opportunities to become deeply immersed in science content and pedagogical content knowledge about science. The LTI ran for three weeks each summer, and included five-to-seven follow-up days. The PTW participants were together for three or four days and received two halfdays of follow-up during the year. And, 
they received on-site support from science supervisors and Leader Teachers who were familiar with the curriculum content. Moreover, these opportunities for professional development were sustained over time, giving teachers time to integrate inquiry into their practice gradually, to reflect on their experience, and to deepen their pedagogical knowledge. The typical teacher attended more than three summer PTWs during the first seven years they were offered.

The ninth standard requires attention to teachers' knowledge of subject matter and their pedagogical content knowledge. The Partnership's intent was to build and deepen teachers' content knowledge and strengthen their pedagogical skills. The LTI concentrated on teacher content knowledge and teachers' mastery of critical concepts in the physical, biological, and earth sciences. Science content was taught through lecture, demonstration, hands-on activities, and reading. The PTWs focused more narrowly on the specific content and concepts in the curriculum modules as well as pedagogical techniques and assessment. Less time was devoted to content mastery in these four-day experiences as management of the unit, logistics, pedagogy, and assessment also had to be addressed. The emphasis tended to be placed on the content that students might have trouble with, and on ways of presenting or explaining that content.

The tenth standard requires utilization of teacher expertise and leadership. Both the LTI and the PTW programs involved teachers and administrators in planning, design, and delivery. Some teachers and local curriculum experts joined MISE staff to plan the LTI, and, of course, the central purpose was to prepare teachers from each school to be Leader Teachers. As we have recounted elsewhere, many of the Leader Teachers played significant roles in the development of curriculum and assessment in their districts as well as serving as mentors and coaches. ${ }^{5} \mathrm{~A}$ different, and more inclusive, strategy was used for the PTWs. Teachers who had been successful in the LTI and other accomplished practitioners were asked to be instructional leaders for the PTWs. Leader Teachers were involved in district professional development planning and in the design and delivery of the PTWs. Members of the PTW instructional teams gained considerable skill and confidence in working with their colleagues. They received guidance from MISE and their team members, and the teams debriefed on a daily basis and reflected on how the activities they had planned had worked and how well they had carried them out. This approach to learning to work with adults proved quite successful, and over the years, this cadre of teachers expanded until each district had a significant number of teachers able to lead professional development.

The eleventh standard requires collaboration among teachers within and across schools. The Partnership used a variety of strategies to foster collaboration among teachers both within and across schools - training Leader Teacher teams, encouraging grade-level teams to attend PTWs together, conducting school meetings, supporting study groups for assessment, and creating electronic networks. The high level of participation in the PTWs over time is just one measure of their success. The Leader Teacher teams were expected to function as units in their schools, to build communities of practice around science, and to encourage teachers to sign up for the summer workshops. The success of these teams varied, depending on the status of the Leader Teachers in the school, the support provided by their

\footnotetext{
${ }^{5}$ See CPRE (1999) and CPRE (2000).
} 
principals, and whether there was time for teachers to meet. In most of the schools, however, they were successful in getting most faculty engaged in improving science instruction. Dozens of teachers were also involved in study groups that worked on the development of performance assessments to be used with the science modules. These teachers also became members of professional communities that cut across school and district boundaries. Many of these teachers later were involved in the Partnership-wide adaptation and administration of TIMSS (Third International Mathematics and Science Study) performance assessments in selected grades. They worked together on revising, scoring, and administering these performance tasks, and also on interpreting the results.

Finally, consistent with the last standard, teachers who participated in the LTI and the PTWs consistently and almost universally reported being treated as professionals. At the instructional team retreats, facilitators modeled, and then made explicit, the relationships that instructors should establish with adult learners. Respect and use of prior knowledge were central themes. In the PTWs, instructors drew upon the knowledge and experience of the participants to discuss management of inquiry in the classroom, common logistical problems and their solutions, and common conceptual misunderstandings and alternative ways to explain key concepts. The effects of this emphasis were apparent in follow-up evaluations: teachers consistently reported that they appreciated being treated as professionals.

In sum, the professional development offered by MISE and its partners satisfied most of the standards we described earlier in this report. In fact, most of these standards were articulated as principles of design at the PTW retreat. Perhaps the only standard that the
Partnership failed to meet consistently was the sixth one: making the evidence supporting their vision of good practice accessible, transparent, and subject to critique. MISE staff were strong advocates of inquiry-centered practice and did not always address its limitations. Inquiry-centered pedagogy and the science modules were generally presented as "best practice" without much discussion of the strength of the evidence supporting these claims. Like most reformers, they appealed to teachers on both philosophical and practical grounds, and drew the strongest support for their advocacy from professional organizations rather than from empirical evidence.

\section{Building District and School Capacity}

Did the Partnership's approach to professional development build district capacity to stimulate and support continuous improvements in teaching? Both the LTI and PTW programs were designed to be capacity-building initiatives. Analysis of interviews conducted by CPRE evaluators with Leader Teachers, principals, instructional team members, and central office staff reveals persuasive evidence that significant changes occurred in the capacity of all four districts. District leaders consistently expressed confidence that their staffs could plan and deliver the high-quality professional development provided under the auspices of the Partnership, and in all four districts, the model of instructional support used in science was extended to other subject areas. The situation in the schools was somewhat more mixed, but most principals and Leader Teachers felt that their schools had gained the capacity to sustain reforms in science teaching and had developed strategies for introducing new teachers to their concepts of good practice. They, too, reported that the Partnership experience had provided 
them with the attitudes, know-how, and tools needed to make improvements in other areas of teaching.

CPRE collected substantial evidence from interviews and observations that Leader Teachers took their responsibilities to provide instructional leadership in their schools and districts seriously. Forty-two Leader Teachers were interviewed during the 1997-1998 school year, and a second sample of 38 were interviewed in the 1999-2000 school year. Based on the analysis of these data, Leader Teachers who took on responsibilities in their schools roughly fell into five categories: serving as on-request resources, providing individual outreach to teachers, providing individual outreach school-wide, providing team outreach school-wide, and serving district-wide needs. Both sets of interviews found considerable variation in the roles played by Leader Teachers across schools, and the second set of interviews revealed a slight decline in Leader Teacher activity.

On-request Resources. Virtually all the Leader Teachers said that they regularly responded to requests for information from other teachers and served as on-request resources in their schools. They assisted individual teachers with science-related questions, explaining key concepts, sharing lesson plans, and helping to set up demonstrations or investigations. For most Leader Teachers, this was just one dimension of their role, but some did not feel comfortable going beyond responding to such requests. Some felt they should not be in other teachers' classrooms and worried that other teachers would resent more proactive roles. In either case, they were uncomfortable taking much initiative to share their knowledge.

Individual Outreach to Teachers. Many of the Leader Teachers reported that they worked on an individual basis with other teachers. They referred to this work as coaching, in which they worked with another teacher over time to help them teach one of the science or mathematics modules, to design or modify assessment tasks that were more authentic or more closely aligned with the unit, or to develop curriculum. Frequently, these other teachers were grade-level partners, or, in a few cases, student teachers.

\section{Individual Outreach School-wide.} Some Leader Teachers reported organizing or implementing activities for groups of teachers or for the whole school. One Leader Teacher said, "My role is building strength at my grade level in a cooperative vein." Leader Teachers from several schools reported collaborating on curriculum with groups of teachers who had participated in the PTWs. A special education Leader Teacher described how she facilitated a workshop on inclusion and inquiry-centered science for her school's staff. Another Leader Teacher explained how she assumed responsibility for revamping the school's science curriculum. Several Leader Teachers mentioned how they coached groups of teachers at their grade level or provided ongoing support to graduates of PTWs.

Team Outreach School-wide. Leader Teachers in about half of the Partnership schools worked as teams to provide activities for their school or community. These activities varied, but were distinctive because the Leader Teachers worked collaboratively in teams, and not just as individuals. In several cases, the collaboration involved the design of workshops for teachers. Other examples included organization of science fairs or science nights for students and parents, and mathematics and science career days for students. In another case, Leader Teachers worked together to develop a schoolwide structure for developing and sharing lesson plans. In a few cases, Leader Teachers developed curriculum 
units around themes (the rainforest in one school, a woodland habitat in another) that they used to model reform strategies for other teachers. These strategies included eliciting student questions, using assessment to gauge prior knowledge, inquiry-centered activities, and linking curricula to standards. One Leader Teacher said, "In the whole school, there has been tremendous growth. As a group of Leader Teachers, we did it [provided support] as necessary. We all did different things to help within the building. It's very informal, but we all get around."

District-wide Influence. A number of Leader Teachers were involved at the district level. Several Leader Teachers led district in-service days. Leader Teachers also assumed an increasingly prominent role in planning and leading PTWs in their districts. Leader Teachers in each district served on science and mathematics curriculum and frameworks committees. Leader Teachers were an integral part of their districts' representation on MISE's Advisory Committee, which brings together leadership groups from the four partner districts to discuss strategic issues and formulating policies and other reforms. A few Leader Teachers mentioned that they represented their districts in speaking at state science conferences.

\section{School Principals and Leader Teachers}

Almost all of the principals reported that they supported the work of the Partnership and the Leader Teachers in their schools. Several principals met regularly with their Leader Teachers, as one principal described, "to foster the Merck initiatives throughout the school." An elementary principal said, "The Leader Teachers have had a presence in the building. They are role models for others to emulate." One principal orga- nized the school schedule so that Leader Teachers could go to other teachers' classrooms to support their science instruction. Several principals from different districts mentioned that schools and districts need to better define the roles of Leader Teachers.

Principal support was the most powerful predictor of reform-based teaching practice. Teacher assessments of the amount of support provided by their principals were statistically associated with reform-based teaching practice (CPRE, 1999). Teachers in schools with supportive principals were far more likely to use inquiry-centered practices than teachers in schools where the school leader was not supportive.

The importance of principals and the variation in their support also was revealed in interviews with Leader Teachers. Leader Teachers from several schools across the Partnership described receiving outstanding support from their principals. "Our principal is $150 \%$ behind the Merck initiative," said one Leader Teacher. A principal in another school held monthly meetings with her Leader Teachers and involved them in school decision-making about science and mathematics. A Leader Teacher from this school commented, "She treats us as leaders. She looks for needs in the building and...uses us as leaders in the school." Another Leader Teacher described how her principal "meets with us to discuss science and mathematics issues before they are brought to the rest of the faculty. We are appreciative that she asks for our input first. She respects us for our efforts with Merck."

Other Leader Teachers described indifferent administrative support in their schools. One Leader Teacher said, "It is passive support. They are supportive but not involved." Another Leader Teacher felt that the continual change in the administrative staff made stable 
support of high-quality instruction impossible. "It is not intentional," she said. "But things are so vague, you just don't know from one day to the next, and these things play against the initiatives such as Merck." In several other cases, Leader Teachers felt there was no place for teacher leadership in their schools, and that authority rested with the administrative staff, not the faculty.

\section{Another Capacity-building Strategy}

The inclusion of accomplished teachers on PTW instructional teams also contributed to the capacity of the four districts. Table 5 shows the general make-up of the instructional teams from 1996 to 2001. The composition of these instructional teams evolved over time; in the first few years, the teams drew heavily on MISE staff and external consultants, but also included some Leader Teachers. The external consultants included individuals from national curriculum development and technical assistance organizations, other science organizations, local and regional universities, and other school districts. By 2001, the team members were predominantly recruited from the ranks of teachers and central office staff from the four partner districts. Thirty-five of the 39 instructional team members offering science PTWs in the summer of 2001 were district staff including 6 from local high schools. This compositional change reflects MISE's efforts to build district capacity to sustain the professional development. Although MISE was initially the force behind the professional development, over time its role was reduced as Leader Teachers gained confidence and took charge and the districts took on increased responsibility for the PTWs.

Interviews with members of instructional teams also indicated that they were assuming leadership positions in their schools and districts. Some had already been playing such roles as they had been Leader Teachers, but others had not. They reported that being members of instructional teams gave them a new status among their peers as well as increased confidence in their knowledge and skills. The experience of designing and leading professional development sessions prepared them to lead professional development in their schools. It also linked them to networks of school and district leaders who were involved in planning the PTWs for their districts and a larger network of educators who were working on these tasks across the Partnership.

One instructional team member who had not been a Leader Teacher described how her role had been transformed:

I have always liked teaching science, and occasionally when I did something that involved parents, my principal took notice. But since I have been doing the PTWs, he asks my advice all of the time, gave me a student teacher for the first time, and even asked me to do a workshop on science for an in-service day.

\section{Table 5. Composition of Instructional Teams for Science Workshops, 1996 to 2001}

\begin{tabular}{lcccccc}
\hline Background & 1996 & 1997 & 1998 & 1999 & 2000 & 2001 \\
\hline Consultants & 4 & 5 & 6 & 11 & 20 & 4 \\
District Staff & 7 & 14 & 24 & 43 & 40 & 35 \\
Total & 11 & 19 & 30 & 54 & 60 & 39 \\
\hline
\end{tabular}

Source: CPRE, 2001 
Another member who had been a Leader Teacher said her colleagues now viewed her differently:

When I was in the Leader Teacher program, I think that some of the other teachers felt that I was trying to make myself important and resented me or just ignored me. But working in the PTWs seems to have changed how they look at me. It took a while, but they now seem to recognize that I know something about science teaching and they are coming to me for help. Two have even asked me into their classrooms to observe.

It is clear from both the survey and interview data that the instructional team members contributed to school and district capacity in several ways: providing their districts with the capacity to sustain the professional development independently, serving as advocates for high-quality professional development, helping build and sustain professional learning communities in their schools, and providing role models for other teachers to take leadership roles.

\section{The Impact on Classroom Practice}

In this section, we examine how the professional development offered by the Partnership affected the classroom practice of participants. To what extent was the knowledge that teachers gained through these professional development experiences translated to classroom practice? This section assesses the evidence of impact on teacher content knowledge and then presents findings from five separate analyses of the impact of Partnership professional development on classroom practice conducted by CPRE between 1998 and 2002.

\section{Teacher Content Knowledge}

Strengthening the content knowledge of teachers was a major goal of the Partnership's professional development program. However, no objective measures of teacher content knowledge were available to the district planning teams, the instructional teams leading the LTI and the PTWs, or the CPRE evaluation team. CPRE's evaluation team did have access to a proxy measure, the number of college science courses taken by the teachers. But this is at best a crude baseline measure for relatively inexperienced teachers. It is less useful as an indicator of the knowledge of experienced practitioners. Classroom observations provide little help in this regard. While observers can identify those with very strong or weak command of their subject, single observations do not provide reliable measures of teachers' practice let alone their content knowledge. So, for the most part, all parties had to rely on teachers' self-assessment of their science knowledge as reported on the workshop surveys. While these measures are not robust, they do reveal that both LTI and PTW participants believed that the professional development strengthened their content knowledge.

Participants in the LTI summer session were asked in September 1996 to evaluate the three-year LTI and indicate how their knowledge and skills had changed as a result of the experience. Figure 2 summarizes their responses. The results suggest that the teachers had gained significant knowledge in the areas of science, inquiry-centered instruction, assessment, and cooperative learning. Increased knowledge of science represented the major area of growth while increased knowledge of assessment was the smallest. Teachers' initial estimates of their knowledge of inquirycentered instruction and assessment techniques were higher than the previ- 


\section{Figure 2. Change in Leader Teachers' Knowledge, Pre- and Post-Mean LTI Ratings}

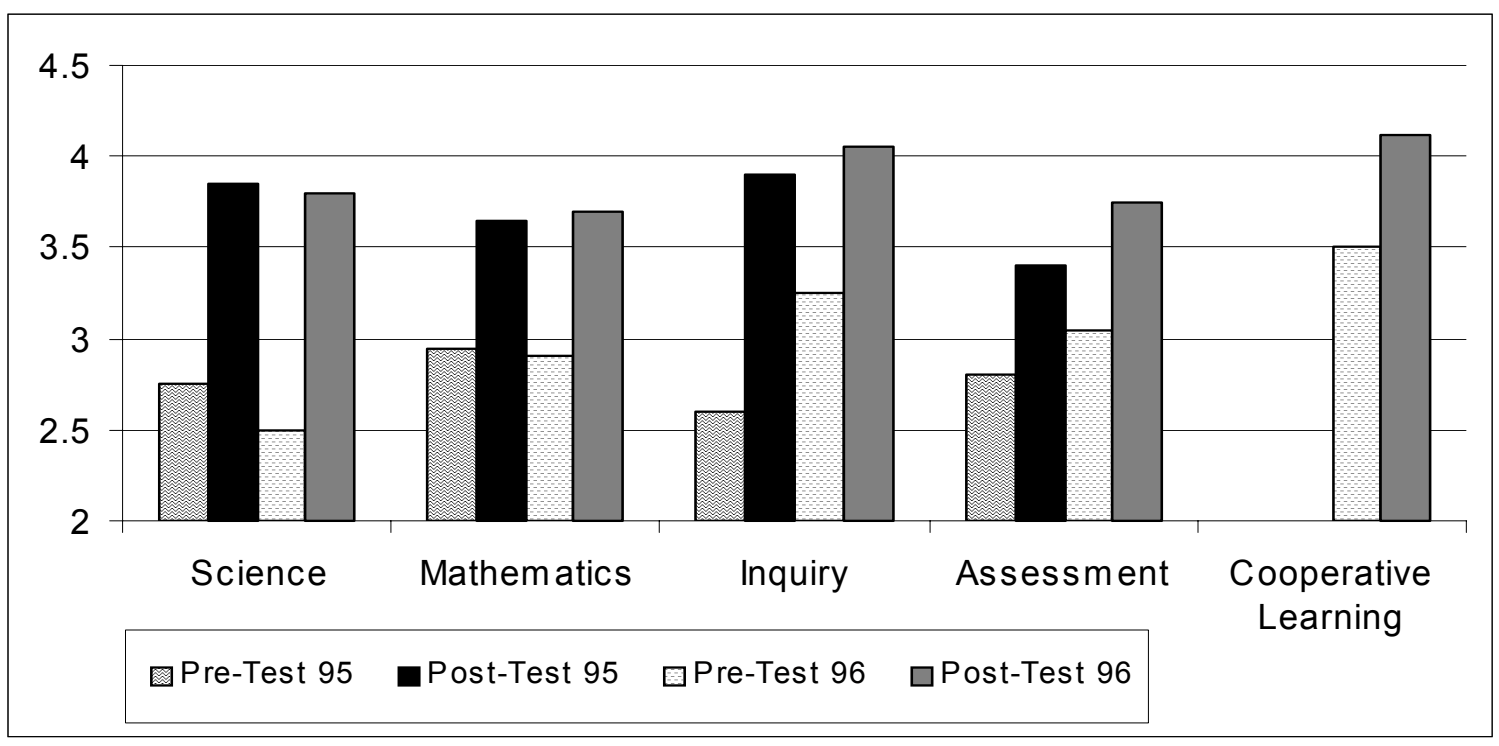

ous year's, suggesting that they perceived a real change in their capacity.

Similar questions were posed to the PTW participants each year. And each year, over $90 \%$ of those attending science PTWs reported that they had increased their knowledge of the subject. This general pattern was confirmed in interviews in which teachers were asked to give explicit examples of the knowledge that they had gained. The teachers also reported that the PTWs provided them with the pedagogical content knowledge they needed to implement the science units successfully. The PTW instructional teams assumed that teachers would need help with the content of new curriculum units and generally relied on anecdotal information to identify these needs. Those who were delivering PTWs previously offered used the archival binders, which included notes from previous trainers about the concepts and topics that were challenging for teachers. The instructional teams also attempted to address needs of individuals through tutoring and coaching within the context of the PTWs, but this was limited by the time available and the needs of the group as a whole. It should be noted that participation in the PTWs was voluntary, and teachers whose content knowledge in science was particularly weak may have chosen not to participate.

The attention paid to the content knowledge of the participants varied somewhat across the PTWs. It seemed to CPRE evaluators that in some cases less attention was paid to content than might have been desirable, given the background knowledge of the workshop participants. The participants themselves obviously did not share this view; they felt that content knowledge was addressed adequately and reported so on the annual CPRE surveys. They felt their content knowledge had been deepened, while both CPRE and MISE staff felt that more attention needed to be given to it.

In summary, CPRE evaluators agreed with most PTW participants who felt that they learned a great deal of science content through the PTWs, but the evidence to support this claim was weak. CPRE's conclusion was based on our observations of the content discussions in the PTWs, the amount of time devoted to such discussions, the attention given to content in the workshop materials, and teacher self-reports about 
what they learned. However, CPRE evaluators also concluded that even more attention needed to be given to content knowledge if the participants were to be expected to make effective use of the new science curriculum.

\section{Classroom Practice}

Analysis 1: Teacher Participation and Changes in Practice. To examine the association between participation in Partnership professional development and instructional practice, CPRE evaluators constructed a statistical model to test the magnitude and significance of this relationship. This model controlled for teacher background and school characteristics. A sophisticated form of regression analysis, hierarchical linear modeling, that recognizes that classrooms are nested within schools, was used (Bryk \& Raudenbush, 1992).

The sample used for this analysis consisted of 334 science teachers. Using items from the HRI surveys, CPRE evaluators constructed a scale of reformed teaching practice in science classes. The items asked teachers how frequently they used certain practices, such as requiring students to supply evidence to support their claims, demonstrating a science-related principle or phenomenon, and using assessment to find what students know before or during a curriculum unit. The number of college science courses taken by the teachers, years of teaching experience, and amount of professional development were used as independent variables to predict teaching practice. The teachers had, on average, 2.36 semesters of college science courses, and 6-10 years of teaching experience. Twenty-eight percent of the 334 teachers reported they had received no science-related professional development during the previous year, 33\% reported receiving between 1 and 39 hours, $17 \%$ reported receiving between 40 and 79 hours, and 22\% reported receiving 80 or more hours.
The most striking result of this analysis was the statistically strong relationship between the amount of Partnership professional development teachers had participated in and their use of inquirycentered pedagogy. After adjusting for differences in teachers' content background, teaching experience, and school environment, teachers with 80 hours or more of professional development were significantly more likely to be using reform-based teaching practices than teachers who had less than 79 hours of professional development.

Figure 3 depicts the relationship between teaching practice and professional development. It presents the predicted use of reform-based teaching practice for the average teacher (that is, a teacher having the sample's average content background and years of experience) from the average elementary school (that is, a school of average size, having the average proportion of students eligible for free or reduced-price lunch, and having average resources and principal support).

Teachers who had no professional development and teachers who had between 1 and 39 hours of professional development had approximately average teaching practice (that is, their scores on the scales developed from the survey items were at about the mean). Teachers who had between 40 and 79 hours of professional development were slightly above average in terms of their use of reform-based teaching practice. Teachers who received 80 or more hours of professional development were much more likely to have altered their practice.

A relationship was found between a teacher's content familiarity, measured by the number of college science courses taken, and reform-based teaching practice. Each additional semester of college science (a proxy for content familiarity) was associated with a statistically significant .11 of a standard deviation increase 
Figure 3. Impact of Professional Development on Teacher-reported Science Teaching Practice

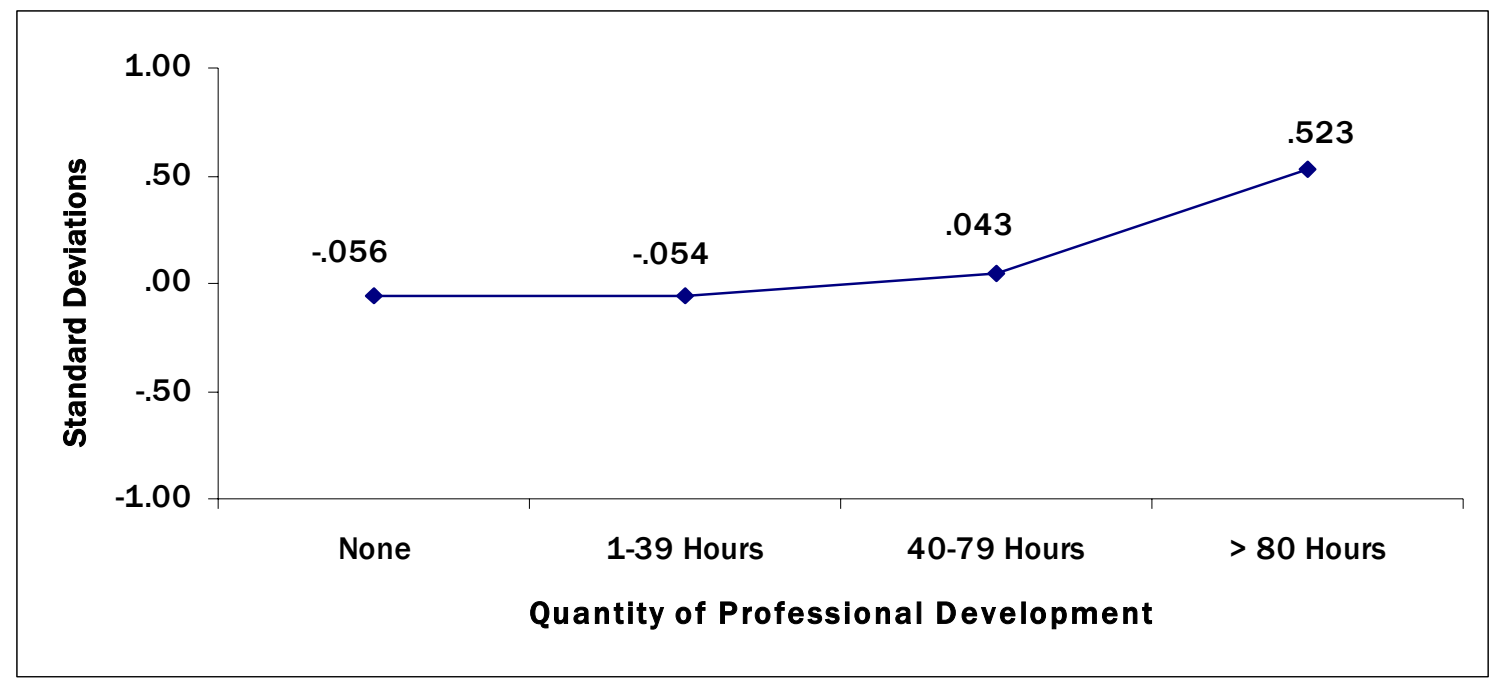

in the model's measure of reform-based teaching practice. This suggests that content knowledge is an important mediator of the use of inquiry-centered instruction.

Analysis 2: Classroom Observations. In 1998, CPRE evaluators observed 68 science classroom lessons. The observers did not know how much Partnershipsponsored professional development the teachers had experienced, and the participation of the observed teachers in Partnership professional development varied widely. Some individuals had received no Partnership professional development although they might have participated in some other science professional development activities during this period. However, as a group, they had limited opportunities as the Partnership was virtually the only provider of professional development in science in the four districts after 1993.

CPRE evaluators used two frameworks for these observations. The first framework, developed by HRI for the LSC initiative, focused on the use of inquiry methods in the classroom, with particular attention to the design, implementation, science content, and equity components of the lesson. A second "authentic pedagogy" framework was based on the work of Fred Newmann and Associates (1996) and focused more on the interactions between students and teachers and teaching for conceptual understanding. This observation framework used three general criteria: construction of knowledge, disciplined inquiry, and value beyond the classroom. The results are presented in Analysis 3.

The HRI Ratings. The HRI classroom observation system uses a seven-point scale ranging from ineffective instruction to exemplary instruction. The score on the scale represents a cumulative judgment based upon the design of the lesson, its implementation, subjectmatter content, and the culture of the classroom. The points on the scale are as follows:

1. Ineffective instruction

2. Elements of effective instruction

3. Beginning stages of effective instruction - low

4. Beginning stages of effective instruction - solid

5. Beginning stages of effective instruction - high

6. Accomplished, effective instruction

7. Exemplary instruction 
Table 6 presents the mean ratings from the CPRE observations of three groups of teachers: Leader Teachers, participants in PTWs, and uninvolved teachers. On average, the observed lessons of Leader Teachers were judged to be slightly below a 4 in 1996-1997 on the HRI scale and over a 5 in 1997-1998. In contrast, the observed lessons of teachers who attended PTWs were judged to be about 3.5 in 1996-1997 and improved to slightly over 4 in 1997-1998. Given that the Leader Teachers were nominated for their program and received intensive professional development for three years, this is not surprising. Most of the teachers attending PTWs in these first two years had received between 32 and 80 hours of professional development at the time of the observations whereas the Leader Teachers had received over 300 hours over three previous years. Lessons of teachers who had not participated in Partnership-sponsored professional development observed in 1997-1998 were judged to be lower in quality than those of either of the other groups.

These results were statistically significant only for Leader Teachers. This may be due in part to the small sample sizes, particularly for 1997. In the spring of 1997, CPRE evaluators observed only 35 science lessons (27 LTI and 8 PTW participants). It is worth reiterating what these differences mean. They show consistent - and in the case of Leader Teachers in science, a statistically significant - change in practice from the spring of 1997 to the spring of 1998. Based on the HRI scale, Leader Teachers grew, on average, from a high 3 to a solid 5. Peer teachers grew from a solid 3 to a 4 . These growth trends are particularly notable given the fact that the majority of the teachers in the sample were observed in both years. These trend lines continued into the 1998-1999 school year.

Beyond the numbers, the classroom observations provided rich glimpses of the ways in which teachers were trying inquiry-centered instruction. Most of the observed lessons incorporated hands-on activities designed for student inquiry and grouped students for cooperative learning. Teachers used class discussions, rubrics, and performance activities for assessment. CPRE evaluators observed many teachers attempting activities that would promote deeper student understanding. These teachers implemented lessons that encouraged students to engage in the scientific process. Most of the observed teachers were aware of the kinds of activities and practices that promoted higher-order thinking in their students, but they often struggled with their implementation. Some teachers appeared to be using a science activity

\section{Table 6. Mean Ratings for Teachers by Type of Professional Development, 1996-1997 to 1997-1998 (with standard deviations in parentheses)}

\begin{tabular}{lcccc}
\hline Category of Teacher & N & $\begin{array}{c}\text { Average Rating } \\
1996-1997\end{array}$ & N & $\begin{array}{c}\text { Average Rating } \\
1997-1998\end{array}$ \\
\hline Leader Teachers & 27 & 3.93 & 25 & $5.30 * *$ \\
& & $(1.49)$ & & $(1.35)$ \\
PTW Participants & 8 & 3.44 & 25 & 4.08 \\
& & $(1.01)$ & & $(1.73)$ \\
Non-participants in Partnership & NA & NA & 18 & 3.26 \\
Professional Development & & & & $(1.86)$ \\
\hline
\end{tabular}

$* \star * p<.001 \quad * * p<.01 \quad p<.05$ 
simply for activity's sake and were not able to articulate how the activity would enrich students' conceptual understanding. Yet even these teachers were in the process of changing their practice.

\section{Analysis 3: Authentic Pedagogy}

Ratings. The teachers observed by CPRE evaluators were also rated using the authentic pedagogy framework. Each lesson was examined for the presence of the following aspects of instructional quality:

- Higher-order thinking skills. Students manipulate information and ideas by synthesizing, generalizing, explaining, hypothesizing, or arriving at conclusions that produce new meaning and understandings for them.

- Substantive conversation. Students engage in extended conversational exchanges with the teacher and/or their peers about subject matter in a way that builds an improved and shared understanding of ideas or topics.

- Deep knowledge. Instruction addresses central ideas of a topic or discipline with enough thoroughness to explore connections and relationships and to produce relatively complex understandings.
- Connections to the real world. Students make connections between substantive knowledge and either public problems or personal experiences.

Overall, science teachers who had participated in Partnership professional development incorporated more higherorder thinking, substantive conversation, and deeper knowledge in their lessons. Table 7 presents observers' ratings on the authentic pedagogy scale for science lessons conducted by teachers having different levels of participation in Partnership-sponsored professional development. The authentic pedagogy ratings range from minimal or no use to high use on a five-point scale.

As the data presented in Table 7 show, Leader Teachers exhibited more aspects of authentic pedagogy than did either teachers attending PTWs or those who had no Partnership professional development. There were statistically significant differences among the three groups in all four areas. Leader Teachers had their classes engaged in more higher-order thinking than teachers who attended PTWs or the non-participants, but there was also a significant difference between PTW participants and non-participants. In classes led by Leader Teachers, CPRE evaluators also observed more complex conversations

Table 7. Average Authentic Pedagogy Ratings of Science Lessons for Teachers with Varying Amounts of Professional Development (with standard deviations in parentheses)

\begin{tabular}{lcccc}
\hline $\begin{array}{l}\text { Type of Professional } \\
\text { Development }\end{array}$ & $\begin{array}{c}\text { Higher-order } \\
\text { Thinking }\end{array}$ & $\begin{array}{c}\text { Substantive } \\
\text { Conversation }\end{array}$ & $\begin{array}{c}\text { Deep } \\
\text { Knowledge }\end{array}$ & $\begin{array}{c}\text { Connections to } \\
\text { the Real World }\end{array}$ \\
\hline LTI $(n=20)$ & 3.40 & 3.55 & 3.35 & 2.79 \\
& $(1.30)$ & $(1.05)$ & $(1.31)$ & $(1.18)$ \\
PTW participant in 1996 or & 2.80 & 2.72 & 2.72 & 1.96 \\
1997 (n=25) & $(1.22)$ & $(1.14)$ & $(1.12)$ & $(.79)$ \\
No MISE Professional & 2.38 & 2.00 & 2.46 & 2.08 \\
Development $(n=13)$ & $(1.04)$ & $(1.15)$ & $(1.13)$ & $(.95)$ \\
\hline
\end{tabular}


(deep knowledge) than in those led by teachers attending PTWs. However, the ratings of both groups were higher than those of non-participating teachers.

Finally, Leader Teachers demonstrated significantly more connections to the real world than did peer teachers, but were no different than non-participants.

Three major points should be taken from this analysis. First, the Leader Teachers' classrooms differed significantly from those of all other teachers. In the classes of Leader Teachers, there were more visible examples of higherorder thinking, more evidence of substantive conversation between students and teachers and among students, and more evident attention to the complex ideas underlying deep understanding. Second, smaller differences were observed between participants in the PTWs and the non-participants. Again, we are reminded that the Leader Teachers were selected because of their interest (and perhaps backgrounds) in science, granted special status in their schools, and therefore might be expected to be more responsive to Partnership professional development. And they had received much more professional development in science by the spring of 1998 than teachers who had only attended PTWs.
Analysis 4: Cumulative Impact of Partnership Professional Development. Evidence has already been presented showing the positive relationship between participation in Partnership professional development and inquirybased teaching. But is there a greater impact for those teachers who participated in more of the professional development? Is more necessarily better? CPRE also examined whether or not attending more than one PTW had even larger effects on classroom practice.

In Table 8 , the average observational ratings of teachers (using the HRI sevenpoint rating scale) who had attended two or more PTWs are compared to those of teachers who attended only one PTW between 1996 and 1999. No distinctions were made concerning the particular content of workshops teachers attended, but rather the hypothesis was that attending more PTWs, regardless of their content, would increase teachers' commitment to and capacity for inquirycentered and standards-based science teaching. The results indicate that, on average, the 11 teachers who attended multiple PTWs had significantly higher observational ratings than the 14 who attended only one PTW $(t=2.07, d f=23$, $\mathrm{p}=.05$ ). While these results suggest that

Table 8. Average Ratings for PTW Participants by Number of PTW Sessions Attended and the Date of the Last Session (with standard deviations in parentheses)

\begin{tabular}{lcc}
\hline Frequency & Number of Observations & Average Rating \\
\hline One PTW & 14 & 3.64 \\
& & $(1.86)$ \\
Two or more PTWs & 11 & 5.00 \\
& & $(1.41)$ \\
Year of Last PTW & & \\
1997 & 10 & 4.00 \\
& & $(1.88)$ \\
1998 & 15 & 4.40 \\
& & $(1.76)$ \\
\hline
\end{tabular}


attending more PTWs might lead to higher levels of practice, we cannot make attributions of causation here. It could be that teachers with higher levels of inquiry-based practices were more motivated to attend the workshops rather than the workshops causing higher levels of practice.

\section{Analysis 5: Analysis of Interview}

Data. In addition to the sample of classroom observations, CPRE also collected data on instructional practice through interviews with teachers, administrators, and district staff. And although self-reports about classroom practice are not as valid as observations (because teachers may be inclined to indicate they are doing what they know is desirable rather than what they actually do), they are a useful complement to observations and help place the observational data in context. Similarly, when survey data are compared over time and are found to be consistent with the patterns emerging from interviews and observations, they strengthen the generalizations that can be made about the trends in classroom practice.

CPRE evaluators found that most over $90 \%$ - teachers attending PTWs initially reported their goal was to learn to use the new instructional modules properly. However, CPRE evaluators found that the Leader Teachers and those who attended multiple PTWs had more ambitious goals that were more closely aligned with the Partnership's vision for reform. They were focused on increasing inquiry-centered questioning and investigations in their classrooms. As one Leader Teacher reported, "...what changed was the focus. We were much more inquiry-based. I tried to do more questioning...had them do more discovery." Examination of the interview data collected over time suggest that the purpose for science instruction changed in many classrooms over the life of the Partnership. As a result, each year, more students were exposed to science instruction aimed at developing understanding and inquiry skills rather than just an interest in science.

Teachers also reported changing the way they conducted lessons in science. Over $80 \%$ of those interviewed reported that they either began to use inquiry or that they increased the use of inquiry in their classes. One primary teacher reported that, in the past, she read a book on science to her class and had students complete worksheets. Now, she sits with the students, presents information, and asks them to explore, observe, and predict. This change in practice led to "students exploring more...being creative in their explaining of science....and has enabled students to take more ownership [in science because] it is more meaningful to them." About two-thirds of those interviewed reported that they were using some form of performance assessment. Many were using performance assessments developed by teachers with the support of MISE.

Most principals and district staff interviewed also reported that teachers' practices have changed, and that they believed that the changes were deep, permanent, and have become part of the school fabric.

Three times between 1994 and 2002, CPRE evaluators conducted interviews with principals in the four districts. On each of these occasions, the vast majority of the principals reported being intellectually and pedagogically excited about the Partnership and expressed strong commitments to inquiry-based learning. They reported that both teacher and student interest in science was growing. They were effusive, exuberant, and inspired by changes in teaching they had witnessed in their buildings. Some typical comments from elementary school principals follow: 
Children love science. I love seeing hands-on, inquiry-based science. It's so cool to see the kids in action. And it's neat seeing teachers allowing kids to investigate and discover.

...we're now approaching science in a whole different way. The old textbook approach is out; students think and look at things analytically. We know how to do an observation and articulate what are in those observations. It's a pleasure to observe the science lessons. The teachers are more knowledgeable about content and process. What it does, it gives them the tools for how to learn. They're getting a philosophy of inquiry.

There are more children involved in science and science is more meaningful. The evidence? I'm a former textbook learner. I was afraid of science. I wasn't excited about science. Now, students are excited; they see it as a natural thing. It's been a very effective Partnership. A lot of teachers have grown. Had it not been for MISE, teachers wouldn't have tried hands-on...I had to learn to touch the worm! And pretend that it didn't bother me. It's been enlightening.

The science program has been greatly expanded and enhanced. Science is emphasized and interesting. It's higherlevel science. Science has a high degree of importance. It's almost equal to other areas. Teachers are more comfortable teaching science.

The staff development has refreshed teachers. I was an elementary teacher and I was afraid of science. Now, it's commonplace. They [teachers] have the same sense of wonder that the kids have!

When I walk into a classroom now, I see a lot of sharing and dialogue and excitement and the teacher roving and asking higher-level questions and having the kids ask, "Let's see what happens." A lot of charts and data collections and connections to everyday life. I'm seeing evidence of their science in the classrooms. Collaborative efforts between students. The collaborative piece, teaming with teachers, sharing discoveries, talking about their findings, sharing their scientific methods...

In addition, CPRE evaluators interviewed district staff members multiple times over the past decade of evaluating the Partnership's work. They also reported profound changes in teacher attitudes and teacher classroom practice. Describing the shifts in attitudes as "cultural changes," one district staff member said:

Teachers are now willing to go to meetings without pay. The reward is intrinsic not extrinsic. A change has occurred in the culture. It's now okay to talk about science.

Another said, "Practices have changed. What teachers have learned will stay with them." A superintendent phrased it more powerfully, "Teachers who have been through MISE have changed forever."

District leaders provided examples of how teachers' practices have changed as a result of their participation in Partnership activities with MISE. One individual described changes in the look of classrooms:

Kids don't sit in rows facing the teacher. They sit in groups of four; there's cooperative learning. There's more movement in class. Classroom management has become [better] because there's more movement and students feel more comfortable and freer to do their work.

Another individual noted the differences in science classes:

Before, teachers might have done a demonstration, kids watched, or all kids 
did the same science project. The text is not the focus anymore. It's inquirybased. Kids are constructing their own lessons. It's hands-on. It's fun for the kids. Science didn't come alive [before].

A third district individual commented on the changes in teachers' confidence as science teachers as a result of their experiences. In turn, teachers' increased confidence has led to changes in science classes, both in pedagogy and curriculum development. She said:

The amount of teachers' energy and their confidence to teach science. They're not afraid to touch animals. That's great! They've given up some control and they're not afraid to do it.

Yet another district individual commented on teachers' raised expectations for professional development:

They've [teachers] all become critical consumers. Before, it was almost expected it [professional development] would be boring. You now know what good, high-quality professional development looks like. You participate, you're an active participant. They [teachers] demand more now. And they've become more vocal. The day of accepting just a lecture is almost over.

Without exception, district leaders and staff from all four districts readily acknowledged that the Partnership had been unprecedented in its commitment, quality, duration, scope, financial support, and focus. One person said:

It's the biggest plus for the science program ever. The amount of professional development, leadership, guidance, purchase of materials. It's just something we wouldn't have been able to do. We would not have had that kind of vision.
This individual's final comment was especially telling: "We would not have had that kind of vision." While there have been many successful schoolbusiness partnerships, MISE's partnership with these four school districts has been unusual in that one of its stated goals has been to challenge the way individuals think about instruction, learning, science, and professional development.

\section{Summary of Impact on Practice}

CPRE analyzed several types of evidence about the effects of teacher participation in Partnership professional development on teachers' instructional practice and content knowledge. A positive relationship was found between participation in professional development (both the LTI and PTWs) and inquiry-based instruction in all of the analyses. In some analyses, the association between participation in the LTI and inquiry-based instruction was stronger than the relationship between PTW participation and this type of instruction. One obvious explanation for this difference might be that the participants in the PTWs simply had less professional development at the time of the data collection than the Leader Teachers. There may not have been sufficient time for the PTWs to have as much impact on practice as the LTI. This is consistent with other findings showing that it takes time for teachers to incorporate new techniques into their practice (Supovitz, 2001). Another reason could be that the LTI directed more attention to the development of content knowledge. A third explanation could be that the intense attention given to the Leader Teachers over the three years of the LTI made them more confident about science teaching and the use of inquiry. Finally, the difference might be due to selection bias; the Leader Teachers were invited to 
participate because of their interest in science and therefore may have been engaged in reformed practice before they were selected.

However, in general, the teachers in the partner districts reported in both surveys and interviews that their teaching had become more inquiry-based as a result of the professional development experiences. Independent observers from CPRE confirmed the changes among teachers who had participated in the LTI and the PTWs. Principals and district staff also confirmed that Partnership professional development had been instrumental in altering instruction in important ways that increased both teacher and student enthusiasm for science.

\section{The Impact on Student Outcomes}

Did the students of teachers who used more reform-based practices perform better than the students of more traditional teachers? Reports from interviews and observations and indepth case studies of several schools suggest that the nature of student classroom experiences and their work dramatically changed over time (Kannapel, 2003; McVay, 2003a, 2003b; Passantino, 2003). Students were spending less time reading textbooks and memorizing terms and definitions and much more time doing investigations, preparing lab reports, writing in their journals, observing demonstrations, and discussing big ideas. Everyone agreed that the students were gaining a better understanding of science and acquiring habits of mind associated with scientific work. But what about hard data on their performance? CPRE examined results from several achievement tests to measure the relationship between Partnership professional development and student outcomes. This report includes the results of analyses using three of these tests - the SAT-9, the New Jersey state elementary and middle school tests (ESPA-Elementary School Proficiency Assessment and GEPA-Grade Eight Proficiency Assessment), and a performance assessment that was composed of items taken from TIMSS (the Third International Mathematics and Science Study). The results point to the need for better assessments and better assessment systems in science.

Sources of Data. Information available on student outcomes in science in the Partnership schools was fragmented and flawed. The primary assessment tool selected by the Partnership, the SAT-9 science test, was not well aligned with the content of the new K-8 science curricula adopted by the districts or with the vision of good science teaching advocated by the Partnership. In fact, given that the science modules were often rotated across classrooms so that each class of students would have covered different units and in a different sequence by the time the test was administered in the spring, it would have been too difficult to achieve alignment with any uniform test. Moreover, the SAT-9 was administered unevenly across the schools, and there were no incentives for either teachers or students to take it seriously. It was simply an additional test administered in grades 5 and 7, and was often referred to as the CPRE or MISE test. For all of these reasons, the results on the SAT-9 may under-estimate what students gained from the reforms.

The state science assessment used in New Jersey in grades 4 and 8 was available only in the latter part of the period covered by this report. The tests were presumably based on the state standards, but the test specifications were quite broad and the items were never released so it was impossible to examine their alignment with the content covered in the fourth and eighth grades in the 
partner districts. Hence, we did not have true baseline data for using these assessments to measure the impact of the Partnership, nor did we have a basis for interpreting the results. We simply cannot make inferences about causal links between reformed practice and student learning given the quality of these assessment data. Therefore, we frame our conclusions as hypotheses based on associations rather than as causal statements.

\section{Analysis 1: Reformed Classroom} Practice and Student Performance. CPRE evaluators constructed multi-level models, again using hierarchical linear modeling, to examine the relationship between teaching practice and student achievement. CPRE evaluators conducted two analyses - one for fifth grade and the other for seventh grade. The fifth-grade sample consisted of 727 students in 34 classes in 17 schools; the seventh-grade sample included 1,236 students in 16 classes in 7 schools. These were the fifth- and seventh-grade students whose teachers had completed the HRI science survey. The outcome variable in the two models was normed student achievement (that is, measured in normal curve equivalents) on the SAT9 science assessment.
Results from these analyses indicated a relationship between teaching practice and student performance for the fifth grade, but not for the seventh grade. In the fifth grade, after adjusting for student and teacher background characteristics and differences between schools, there was a statistically significant increase in student performance associated with changes in teaching practice. An $8 \%$ difference in student performance on the SAT-9 assessment was found between students with teachers using average teaching practice and students whose teachers used reformed practice. In the seventh grade, no detectable differences were found.

Figure 4 is a pictorial representation of the relationship between standardsbased teaching practice and student performance. After holding constant differences in student background, teacher background, and schools, fifthgrade students, on average, scored 50 on the SAT-9. Increased use of reformed practice, as reported by teachers, was linked to gains in student achievement. For the seventh grade, the line is flat, meaning that no statistically significant impact on performance was associated with differences in practice. The lines for

\section{Figure 4. The Relationship Between Standards-based Teaching Practice and Student Performance}

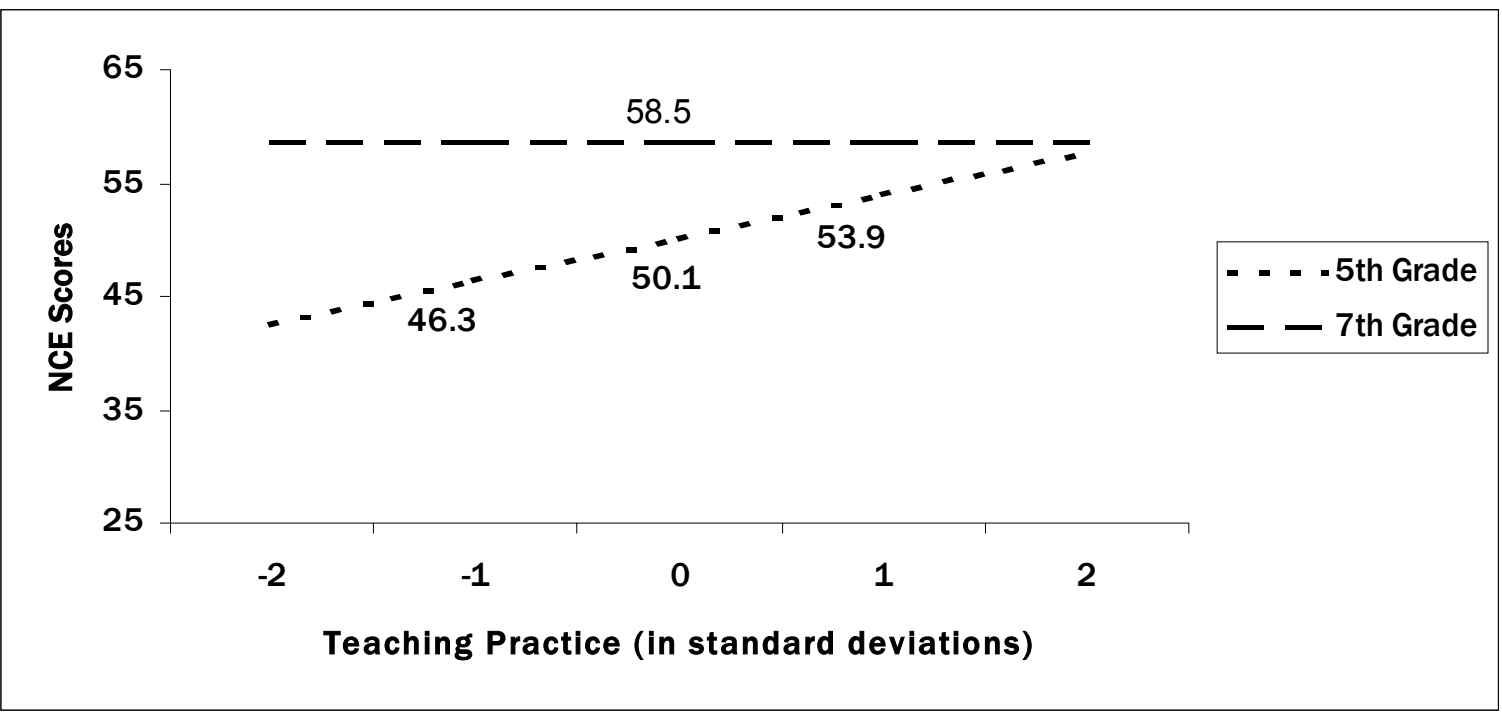


both grade levels are dashed to show that these test scores are derived, not actual scores.

Finally, the qualitative data shed some light on these issues. Teachers and principals revealed in interviews that students' interest in and enthusiasm for science were greater than in the past when the science curriculum was textbook based. A hands-on approach was clearly engaging students more and making good use of their energies, and the inquiry-based curriculum was making them feel like real scientists - forming hypotheses, thinking critically, and using resources to answer their own questions. Teachers and students alike gave science higher priority. This is reflected in the observations of many teachers that students often pleaded with them to do science every day and were disappointed on days when it would not be covered.

Analysis 2: Breadth and Depth of Professional Development and Student

Outcomes. After determining that there was a positive relationship between the participation of individual fifth-grade teachers in Partnership professional development and student achievement in their classes, CPRE evaluators looked at whether school-wide teacher involvement in the Partnership program was related to student outcomes. It was hypothesized that as the number of teachers in a school participating in the Partnership professional development increases, the proportion so engaged might reach a tipping point after which inquiry-centered instruction became the norm and even teachers who were not participating would also adopt the instructional practices, and that this level of engagement might affect schoolwide student achievement. A second hypothesis focused on Leader Teachers. The argument was that if a small number of teachers participated intensely in the Partnership professional develop- ment, they might become instructional leaders in their schools, share their ideas and materials, and shape the schoolwide norms of practice.

To test these two hypotheses, CPRE conducted an analysis of primary teachers using the results of the third-grade performance assessment conducted by the Partnership and the results of the fourth-grade state science assessment for the three New Jersey districts. Measures of the percentage of teachers in a school who participated in Partnership professional development and the amount that they had received were used as measures of the breadth and depth of the saturation of the Partnership's professional development. These are measures of the degree to which a professional community in a school was engaged in the professional development. The breadth and depth variables were created by aggregating the individual teacher participation data to the school level. All types of Partnership professional development were included - the LTI, PTWs, service on instructional teams, and participation in assessment projects.

The measure of breadth was the percent of teachers in a school who had experienced more than one PTW between 1996 and 2001. The means for this variable in the three New Jersey districts were $84.3 \%$ for grades $\mathrm{K}-4$ and $83.5 \%$ for grades K-3. Depth was the percentage of teachers within a school who had participated in more than 200 hours of Partnership professional development across the five years. The means for this indicator in the three New Jersey districts were $22.9 \%$ for grades $\mathrm{K}-4$ and $20 \%$ for grades $\mathrm{K}-3$. This measure is fairly high because the original Leader Teachers all participated in 300 hours of professional development, and most schools had two or three such teachers in their primary grades. The depth measure can be viewed as an indicator 
Table 9. Breadth and Depth of Saturation, Grades K-4 - New Jersey Districts

\begin{tabular}{lccccc}
\hline $\begin{array}{l}\text { Saturation } \\
\text { Variable }\end{array}$ & Mean & Minimum & Maximum & $\begin{array}{c}\text { Standard } \\
\text { Deviation }\end{array}$ & $\begin{array}{c}\text { Number of } \\
\text { Cases }\end{array}$ \\
\hline Breadth & 84.3 & 45.5 & 100.0 & 16.1 & 13 \\
Depth & 22.9 & 11.1 & 46.0 & 10.6 & 13 \\
\hline
\end{tabular}

of the leadership cadre within the schools. A school was characterized as having high depth if at least $20 \%$ of the teachers within it had more than 200 hours of professional development during the five years. A school qualified as having high breadth if greater than $84 \%$ of teachers (the mean) had attended at least one professional development workshop from 1996 to 2001.

In this analysis, CPRE examined the relationship between the measures of the breadth and depth of professional development in the three New Jersey districts and the results on the fourthgrade state science assessment - the New Jersey ESPA (Elementary School Proficiency Assessment) - for three years and one year of the performance assessment scores (third grade). K-4 teachers in the three New Jersey districts were used for the analysis of the fourthgrade ESPA results. K-3 teachers in all four participating districts were used for the analysis of the third-grade performance assessment results. The teachers in both samples were current as of the 2000-2001 school year. Thirteen New Jersey schools were included in the first analysis and 28 schools from all four districts were included in the second analysis. Tables 9 and 10 provide the results of the breadth and depth analyses.

Tables 9 and 10 reveal that the breadth of participation in professional development was positively related to ESPA scores, but it was not strongly related to the performance assessment scores. The depth measure was not a good predictor of improved performance. It was not strongly related to the
1999 ESPA scores, 2001 ESPA scores, or the performance assessment scores, and was negatively correlated with the 2000 ESPA scores. Since the depth measure was a poor predictor, it did not make sense to combine it with the breadth measure. Breadth of participation appeared to be the aspect of saturation in a school that was related to higher performance. The analysis, then, focused on breadth and depth individually.

Because the number of cases was small, it was hard for statistical estimates, such as correlations, to reach significance levels. However, since the Partnership was engaged in districtwide reform, we were looking at the entire population of $\mathrm{K}-4$ teachers within the three New Jersey districts (for the ESPA scores) and the entire population of K-3 teachers within all four Partnership districts (for the performance assessment analysis). So we concluded that these estimates were true for these populations, regardless of their significance levels. However, we could not reach conclusions that extend beyond these specific populations.

The next step was to examine whether the relationship between independent and dependent variables was curvilinear. This was done only for the breadth variable, since there was not a substantial relationship between the depth measure and school mean scores. The results showed that the relationship between broad participation in professional development and the 2001 ESPA scores was curvilinear. Figure 5 shows that a curvilinear model fits the data better and explains more of the test score variation. The effect of the breadth 
Table 10. Breadth and Depth of Saturation, Grades K-3 - All Districts

\begin{tabular}{lccccc}
\hline $\begin{array}{l}\text { Saturation } \\
\text { Variable }\end{array}$ & Mean & Minimum & Maximum & $\begin{array}{c}\text { Standard } \\
\text { Deviation }\end{array}$ & $\begin{array}{c}\text { Number of } \\
\text { Cases }\end{array}$ \\
\hline Breadth & 83.5 & 31.0 & 100.0 & 17.7 & 28 \\
Depth & 20.0 & 0 & 62.5 & 14.8 & 28 \\
\hline
\end{tabular}

variable was fairly flat until $78 \%$ or more of the teachers in a school were engaged in Partnership professional development. The relationship was positive from that point forward except for one case. This suggests that the tipping point for instructional reform might be much higher - at least in science - than is usually assumed by school reformers. A rather high proportion of teachers had to be engaged before positive effects on student achievement were observed on the results of the 2001 ESPA. However, the results of the analysis were mixed as the relationship between the breadth variable and the 1999 ESPA scores was not curvilinear.
The results shown in Table 11 indicate that the breadth of teacher participation in professional development was positively related to the 1999 and 2001 ESPA science scores. The relationship between the 2000 ESPA score and breadth was not substantial. There is a curvilinear relationship between breadth of professional development and the 2001 ESPA scores. This relationship is fairly flat until about $78 \%$ of a school's faculty has experienced at least one form of professional development. While breadth appears to be related to higher scores, the depth of participation does not.

Figure 5. Elementary School Proficiency Assessment 2001 General Education School Mean

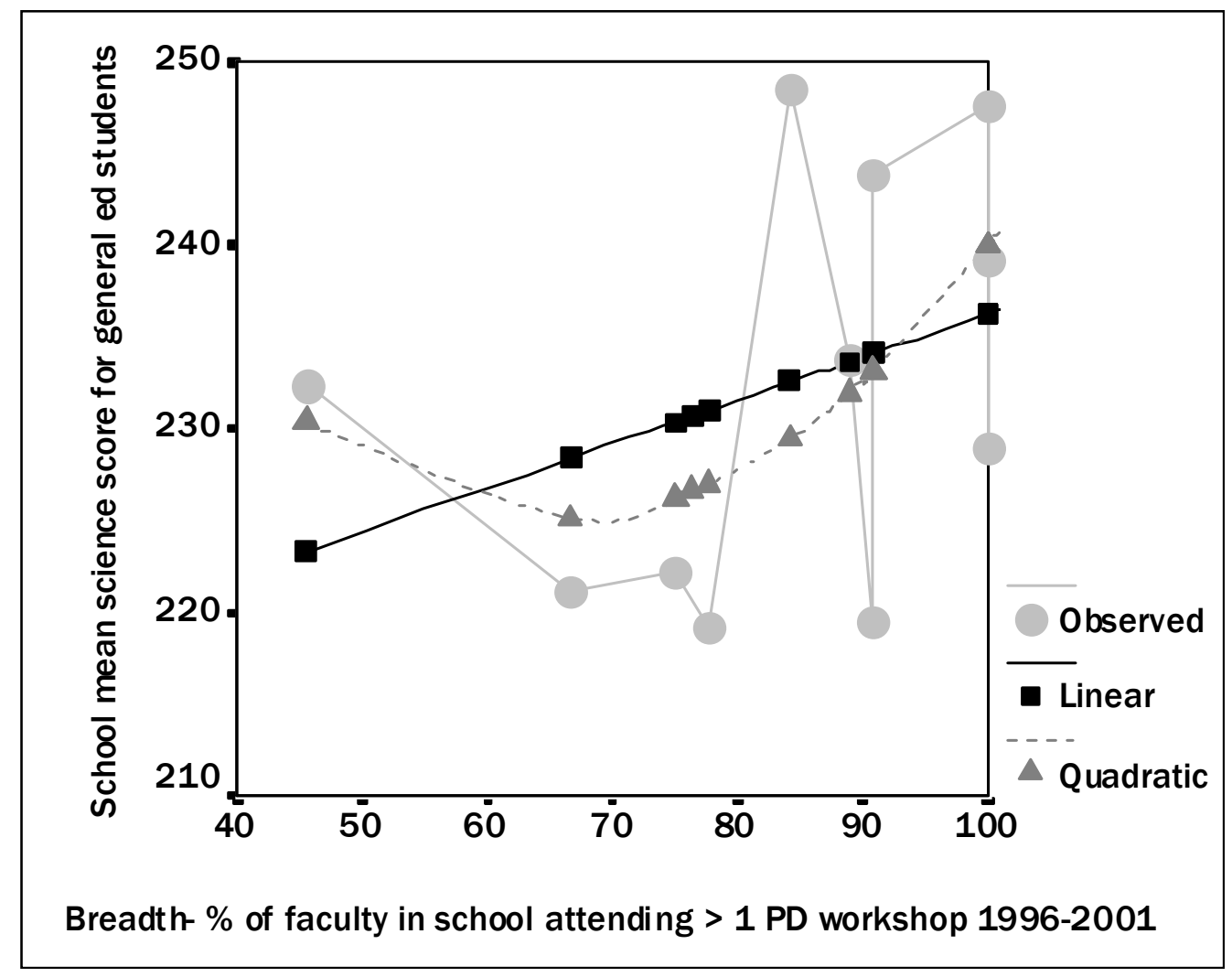


Table 11. Zero-order Correlations Between Breadth and Depth of Professional Development and Science Assessment Results

\begin{tabular}{lcccc}
\hline & \multicolumn{3}{c}{} & $\begin{array}{c}\text { Performance Assessment } \\
\text { Scores }\end{array}$ \\
\hline Test date & 1999 & 2000 & 2001 & $2000-2001$ school year \\
Breadth & .261 & .023 & .398 & -.032 \\
Depth & -.058 & -.314 & .013 & .036 \\
Number of cases & & $13^{*}$ & & 28 \\
\hline
\end{tabular}

* Total number of cases across all three years.

These data suggest that achieving broad faculty participation in professional development may be more important than providing intense experiences of some teachers. In the Partnership schools, having a large number of teachers who have had some professional development is more strongly associated with student performance than having a small number of teachers who have been deeply engaged in professional development. On the one hand, these findings make common sense. If more teachers are receiving training, more will be using inquiry methods in their classrooms, and more students will be exposed to inquiry science. The findings are also consistent with studies of professional community that have shown that having a shared vision of good practice and a common language to discuss practice facilitate the improvement of classroom practice. Also, they are consistent with earlier CPRE findings about the effectiveness of Leader Teachers in spreading inquiry methods within their schools. Some of the Leader Teacher teams were unable to have much impact on the practices of their colleagues because they lacked the opportunity to work with them and the creation of such opportunities were obstructed by norms of teacher autonomy and privacy, competing instructional priorities, schedules, and lack of principal support.

The findings are encouraging because they are consistent with MISE's theory of action. The provision of broad access to professional development combined with on-site support contributed to improved science instruction, which in turn contributed to better student outcomes. While not definitive, this analysis suggests that more refined work using better-aligned outcome measures, student-level performance data, and better measures of school conditions might reveal even stronger relationships.

\section{Summary: The Impact of Professional Development on Student Outcomes}

Although hampered by inadequate measures of student performance in science, CPRE conducted two analyses of the impact of the Partnership's work on student outcomes. The first examined the relationship between teacher use of reform-based classroom practice and student achievement in science and the other examined the relationship between levels of participation in MISE professional development in schools and school-wide student achievement. In the first study, which used hierarchical linear modeling, a statistically significant relationship between reform-based teaching practice and student achievement was found in the fifth grade, but not the seventh grade. In the second study, CPRE analyzed the breadth versus depth of participation in MISE professional development. The main finding was that while breadth of teacher participation in the New Jersey 
Partnership schools was related to higher student scores on the New Jersey state test (Elementary Science Performance Assessment), the depth of their participation was not. These results suggest that reaching a broader audience of teachers may help spread the reform vision and impact student learning more than helping a small group of teachers achieve deep understanding. Of course, MISE and the Partnership did both, and the interactions between the capacity and commitment of the Leader Teachers and the breadth and depth of the participation in the PTWs are not clear. It may be that broad participation helps build a learning community committed to the reform and produces the social pressures and supports needed for sustained change. Clearly, a small group of trained teachers can choose to keep new knowledge about content and pedagogy to themselves or they can share it with colleagues and promote the growth of others. Which they choose to do may depend on the nature of a school's professional community and on its leadership.

\section{Lessons and Challenges}

What lessons can be drawn from the experience of MISE and the Partnership? It seems to us that there are some important ones for those who want to improve the quality of teaching, those who plan professional development, and leaders of reform support organizations that work with schools. In our view, these lessons are:

1. The importance of being both systemic and specific. MISE took a systemic approach to reform in the partner districts, but they also realized that teachers needed a concrete vision of good science teaching, good instructional materials, and accessible, practical professional development. They did not fall into the trap of believing that curriculum stan- dards, aligned policies, and accountability procedures would be sufficient to bring about the desired changes in classroom practice. Their specificity about high-quality science education that enabled them to work with their partners to build a solid science curriculum and design professional development whose utility was recognized and embraced by the vast majority of teachers. In addition, the development and recognition of Leader Teachers and the engagement of district staff in the work made the Partnership's professional development more compelling and more powerful than it would have been otherwise. Neither aligning local policies with content standards nor providing standards-based professional development probably would have produced the same results on their own. The combination led to the development of district and school cultures and contexts in which the professional development was useful, valued, and shared.

2. The effectiveness of a comprehensive approach to professional development. The general professional development model used by the Partnership combined extended immersion in curriculum content and pedagogy with strong follow-up support. Over time, this general model for teacher learning led to significant changes in classroom practice. Their experience shows that the combination of off-site immersion in content and pedagogy and on-site support and reflection is a powerful strategy for promoting teacher learning and changing classroom practice.

3. The importance of offering teachers recurrent opportunities to participate in professional development. If the professional development is to be practical, it must be focused on 
specific chunks of curriculum. If it is to be effective, it must be intense enough for teachers to get deeply engaged in the subject matter and pedagogical issues surrounding it. Therefore, to have an impact on the entire curriculum, teachers must have repeated opportunities to participate over a relatively long period of time. In this case, each summer, they could take one or even two new PTWs and over three or four summers, they would have covered the backbone of the curriculum at their grade level.

4. The enormous benefits of developing, using, and respecting Leader Teachers. The development of teacher leadership through the LTI and the instructional teams was another key to MISE's success. These teachers not only provided on-site support for other teachers attempting to use inquiry-centered approaches, they also recruited colleagues into the PTWs and built communities of practice in their schools that sustained teacher involvement and began a process of continuous improvement through dialogue, reflection, and collaboration. The development and use of Leader Teachers not only built local capacity to design and provide professional development, but also altered district and school cultures by redefining the roles available to teachers and generating new respect for their expertise.

5. The importance of building principals. CPRE's analyses show that the understanding and support of principals influenced the impact of professional development on classroom practice and teachers' roles. This was true for the Leader Teachers and for those who participated in the PTWs. MISE initially involved the principals in the Leader Teacher program and then neglected them for several years. Feedback from their evaluation alerted them to this problem, and they responded with principals' institutes that helped principals understand the vision, gave them tools to monitor its enactment and spread, and helped principals recognize the need to use teacher expertise to build effective communities of practice.

6. The importance of persistence over time. MISE invested in a long-term partnership with the four districts that allowed for the development of shared understandings and a common culture that sustained the work. The PTWs and the Partnership's follow-up support provided time for teachers to master new content, integrate new strategies into their practice, reflect on the responses they were getting from their students, and engage in dialogue with others who were trying similar approaches. Teachers were able to attend PTWs each summer if they wished and the data show strong relationships both between their extended engagement in learning and the changes they made in their practice. It takes considerable time and support to make inquirycentered instruction the norm in classrooms. Teachers showed the greatest change in practice after three years of participation and more than 80 hours of professional development. Prior to that tipping point, most teachers made only incremental changes in their practice.

7. Using tools as mechanisms for transferring new knowledge. MISE's vision of inquiry-centered instruction guided its work, but it was the development and selection of tools that embodied the vision - curriculum frameworks, science modules, rubrics, performance assessments, and observation instruments - that allowed teachers and administrators to transform the vision into practice. 
8. The importance of reinforcing reformed practices in the workplace. MISE's work shows that high-quality, high-utility professional development can attract teachers and that many of them will continue to participate over time. Volunteerism generally works, but not all teachers will participate in enough summer institutes to reach a tipping point in their practice. This observation, along with the finding that a relatively high proportion of teachers had to participate before school-wide effects on performance were realized, points to the need for robust, on-site followup support.

9. The relationship between coherence, sustainability, and impact. There was considerable turnover in the four districts during the period described in this report. Staff mobility and turnover mean that access to curriculum-based professional development has to be regular and ongoing to have powerful effects on practice. By aligning their policies around a specific vision of good practice, offering a menu of workshops that were periodically repeated, and providing new teachers with orientations to inquiry-centered instruction, the districts were able to develop and sustain particular norms of good practice.

10. The importance of breadth as well as depth in the design of reform strategies. One of the strengths of the LTI was that it concentrated on increasing teachers' knowledge of science and skill at designing and managing student inquiry. The strength of the PTWs was that they reached a wide audience, so that many teachers in a school experienced similar professional development and shared a common vision of good practice. Both gave teachers a common experience from which they built professional communities.
While the notion that depth is preferred to breadth is a popular idea - less is more - the evidence suggests that this argument may not apply to school change. It was broad participation in professional development that was shown to be positively related to school-wide student achievement, not the depth of the experiences of Leader Teachers. While it is no doubt true that the best outcomes would be achieved by a program that provided both deep engagement in the content and broad participation, the evidence should raise a red flag for those who design programs for small numbers of teachers and hope that the knowledge they gain will be transferred to others.

11. The importance of seeking and using evaluative feedback. Many organizations hire evaluators, but only some make use of them. MISE has been, and continues to be, a learning organization. MISE has supported evaluation of its work and paid close attention to the results. Over the years, CPRE evaluators have provided regular feedback on the professional development provided by MISE and the Partnership and annually offered recommendations for the improvement of the entire initiative. MISE staff have listened to this feedback, reflected on it, and typically made modifications to their approach. Most of the recommendations offered in CPRE's annual reports have resulted in MISE taking action. The title of this report, "Getting It Right," reflects this commitment to continuous improvement.

\section{Challenges and Issues}

Challenges are simply lessons of a different kind, pointing to problems that must be addressed, pitfalls to avoid, or 
obstacles to be overcome. The Partnership certainly faced some challenges, and others can benefit from its experience.

1. First, there is the very important problem of identifying measures of student learning that are sensitive to the outcomes being sought by the reforms. Here, the principal investigator of the CPRE evaluation team must take responsibility for providing bad advice. In retrospect, it would have been better to have used some form of student work sampling or to have developed some common assessments for use with a sample of key science modules. Either strategy would have provided MISE and the Partnership with useful measures of progress over time and supported studies of the relationships among participation in the professional development, teaching practices, and student performance. It also would have permitted evaluation of the effectiveness of the modules themselves. Instead, concerned about possible negative reactions from teachers worried about the use of student assessment data to assess their teaching performance, CPRE recommended use of the SAT- 9 and the state science assessment. Neither of these measures proved to be wellaligned with the changes taking place in teaching and learning. As a result, the evidence available on the impact of Partnership professional development on student learning is limited, and we cannot adequately determine how much impact the reforms in teaching actually had on student performance. Clearly, the standardized tests were not aligned with inquiry-centered instruction or the science content being taught, and some of the most important effects of inquiry-centered teaching were not captured by these measures as they are not designed to assess students' understanding of the scientific process or their willingness to engage in observation, analysis, and explanation. Data from interviews, classroom observations, and teacher surveys all suggest that there have been significant effects on student performance, but this is less persuasive than having robust and independent measures. It will be important for future studies to use measures that are more closely aligned with the reforms being sought in science teaching.

2. A similar problem arises from the lack of appropriate and acceptable measures of teachers' knowledge of the subject matter. While tests of science knowledge exist, there are not good measures of pedagogical content knowledge available. Such instruments would allow for the customization of professional development to meet the needs of individual teachers and improve the overall design of learning opportunities for teachers. We also say acceptable because the problem is broader than the lack of adequate measures; it also involves the willingness of teachers to subject themselves to tests of their content knowledge. While the reluctance of experienced teachers to take subject-matter tests is understandable, it obstructs the customization of professional development and means that knowledgeable and skilled teachers have to be subjected to professional development curricula designed for teachers who are less well prepared.

3. Variations in the science modules in the four Partnership districts and the practice of rotating science modules across classrooms in several of the districts made it difficult to build professional learning communities in the schools, hampered the design of follow-up procedures, and limited the ability of the Partnership to use 
review of student work as a vehicle for teacher learning. The Partnership would have been more effective if all of the districts had adopted the same science units at the same grade levels, and if all teachers had used them in the same sequence and at roughly the same time. This would have permitted the follow-up support to focus more attention on student work and would have allowed more cross-school networking and benchmarking.

4. While the visibility and status of science education was raised enormously in the four districts, it was a constant struggle in some schools to maintain a focus on science. The attention directed to the results of state assessments in literacy and mathematics by some school principals was a perpetual threat to the Partnership's work. Even the introduction of a state assessment in science in New Jersey did not solve this problem as some principals adhered to the view that literacy and mathematics were foundational subjects and science was not. Yet, science provides an intellectual framework and a perspective on the world that also is foundational. MISE attempted to address this by designing PTWs on science and literacy that helped teachers address literacy skills through materials containing scientific content. But the problem of keeping the quality of science teaching, and time for inquiry, on the agenda is a continuing challenge.

These challenges are important, and should be addressed, but they should not overshadow what MISE has accomplished in the past decade. MISE and the Partnership have provided hundreds of teachers in the four partner districts with high-quality professional development for almost a decade. They have improved teaching and learning in science, and indirectly in other subjects, in hundreds of classrooms. They have demonstrated that the capacities and cultures of local schools and districts can be changed in fundamental ways. The quality and impact of the professional development experiences provided has remained high even as the responsibility for planning and delivering them has been shifted to Leader Teachers and district staff. Science teaching in the four partner districts is fundamentally different now from what it was when MISE began its work. MISE's theory of action has yielded good results, and because it continues to work to "get it right" by listening, collaborating, and redesigning, it is likely to yield even better results in the future. 


\section{References}

American Federation of Teachers. (1999). Principles for professional development: AFT's guidelines for creating professional development. Washington, DC:

Author.

Birman, B., Desimone L., Garet, M., \& Porter, A. C. (2000). Designing professional development that works. Educational Leadership, 57(8), 28-33.

Bryk, A. S., \& Raudenbush, S. (1992). Hierarchical linear models. Newbury Park, CA: Sage Publications.

Cohen, D. K., \& Hill, H. C. (2001). Learning policy. New Haven, CT: Yale University Press.

Consortium for Policy Research in Education. (1999). A close look at effects on classroom practice and student performance: A report on the fifth year of the Merck Institute for Science Education. Philadelphia: Author.

Consortium for Policy Research in Education. (2000). Deepening the work: $A$ report on the sixth year of the Merck Institute for Science Education. Philadelphia: Author.

Consortium for Policy Research in Education. (2001). Steady work: A report on the seventh year of the Merck Institute for Science Education. Philadelphia: Author.

Corcoran, T. B. (1995). Helping teachers teach well: Transforming professional development (CPRE Policy Brief No. RB16). New Brunswick, NJ: Consortium for Policy Research in Education, Rutgers University.
Corcoran, T. B. (2003). The Merck Institute for Science Education: A successful intermediary for school reform (CPRE Research Report No. RR-052). Philadelphia: Consortium for Policy Research in Education, University of Pennsylvania.

Corcoran, T. B., \& McDiarmid, W. (2000). Promoting the professional development of teachers. In R. Pankratz \& J. Petrosko (Eds.), All children can learn: Lessons from the Kentucky reform experience. San Francisco: Jossey-Bass.

Darling-Hammond, L. (1997). Doing what matters most: Investing in quality teaching. New York: National Commission on Teaching and America's Future, Teachers College, Columbia University.

Desimone, L., Porter, A. C., Garet, M., Suk Yoon, K., \& Birman, B. (2002). The effects of professional development on teachers' instruction: Results from a three-year longitudinal study. Educational Evaluation and Policy Analysis, 24(2), 81112.

Elmore, R. F. (2000). Building a new structure for school leadership. Washington, DC: Albert Shanker Institute.

Elmore, R. F. (2002). Bridging the gap between standards and achievement: The imperative for professional development in education. Washington, DC: Albert Shanker Institute.

Elmore, R.F., \& Burney, D. (1997). Investing in teacher learning: Staff development and instructional improvement in community school district \#2, New York City. New York: National Commission on Teaching and America's Future, Teachers College, Columbia University, and Philadelphia: Consortium for Policy Research in Education, University of Pennsylvania. 
Haslam, M. B., \& Seremet, C. P. (2001). Strategies for improving professional development: A guide for school districts. Washington, DC: New American Schools.

Kannapel, P. J. (2003). Three Bridges and Holland Brook Elementary Schools, Readington Township, NJ. Philadelphia: Consortium for Policy Research in Education, University of Pennsylvania.

Killion, J., Munger, L., Roy, P., \& McMullen, P. (2003). Training manual for assessing impact: Evaluating staff development. Oxford, OH: National Staff Development Council.

Lieberman, A., \& Wood, D. R. (2002). Inside the National Writing Project. New York: Teachers College Press.

Loucks-Horsley, S., Love, N., Stiles, K. E., Mundry, S., \& Hewson, P. (2003). Designing professional development for teachers of science and mathematics, second edition. Thousand Oaks, CA: Corwin Press.

Loucks-Horsley, S., Stiles, K. E., \& Hewson, P. W. (1996). Principles of effective professional development for mathematics and science education: A synthesis of standards. NISE Brief, 1(1), 1-6.

McVay, S. (2003a). Franklin Elementary School, Rahway, NJ. Philadelphia: Consortium for Policy Research in Education, University of Pennsylvania.

McVay, S. (2003b). Inglewood Elementary School, Lansdale, PA. Philadelphia: Consortium for Policy Research in Education, University of Pennsylvania.

National Commission on Teaching and America's Future. (1996). What matters most: Teaching for America's future. New York: Author.
National Research Council. (1996). National Science Education Standards. Washington DC: National Academy Press.

National Staff Development Council. (2001). NSDC standards for staff development. Oxford, OH: Author.

Newmann, F. M., \& Associates. (1996). Authentic achievement: Restructuring schools for intellectual quality. San Francisco: Jossey Bass.

Olson, S., \& Loucks-Horsley, S. (Eds.) (2000). Inquiry and the National Science Education Standards: A guide for teaching and learning. Washington, DC: National Research Council.

Passantino, C. (2003). Highland Avenue School, Linden, NJ. Philadelphia: Consortium for Policy Research in Education, University of Pennsylvania.

Pennell, J. R., \& Firestone, W. A. (1996). Changing classroom practices through teacher networks: Matching program characteristics with teacher characteristics and circumstances. Teachers College Record, 98, 46-76.

Spillane, J. P., Halverson, R., \& Diamond, B. (2001). Investigating school leadership practice: A distributed perspective. Educational Researcher, 30(3), 23-28.

St. John, M., \& Stokes, L. (2003). The National Writing Project: Five key evaluation findings (Slide presentation). Inverness, CA: Inverness Research Associates.

Supovitz, J. A. (2001). Translating teaching practice into improved student achievement. In S. H. Fuhrman (Ed.), From the Capitol to the classroom: Standards-based reform in the states (pp. 8198). Chicago: University of Chicago Press. 
Supovitz, J. A. (2003). Evidence of the influence of the National Science Education Standards on the professional development system. In K. S. Hollweg \& D. Hill (Eds.), What is the influence of the National Science Education Standards? Washington, DC: National Academy Press.

Supovitz, J. A., Mayer, D., \& Kahle, J. B. (2000). The longitudinal impact of inquiry-based professional development on teaching practice. Educational Policy, 14(3), 331-356.

Supovitz, J. A., \& Snyder Taylor, B. (2003). The impact of standards-based reform in Duval County, Florida, 19992002. Philadelphia: Consortium for Policy Research in Education, University of Pennsylvania.

Supovitz, J. A., \& Turner, H. M. (2000). The effects of professional development on science teaching practices and classroom culture. Journal of Research in Science Teaching, 37(9), 963-980.

Wilson, S. (2003). California dreaming.

New Haven, CT: Yale University Press. 


\section{Appendix A. Annual Reports on CPRE's Evaluation of the Merck Institute for Science Education}

The following evaluation reports are available by contacting (215) 573-0700, extension 1 or via email at cpre@gse.upenn.edu.

Consortium for Policy Research in Education. (1995). The CPRE evaluation of the Merck Institute for Science Education. New Brunswick, NJ: Author.

Consortium for Policy Research in Education. (1996). Reforming science education: A report on the second year of the Merck Institute for Science Education partnership, 1994-95. Philadelphia: Author.

Consortium for Policy Research in Education. (1997). Scaling up reform in science education: A report on the third year of the Merck Institute for Science Education, 1995-96. Philadelphia: Author.

Consortium for Policy Research in Education. (1998). Expanding the breadth and effects of reform: A report on the fourth year of the Merck Institute for Science Education, 1996-97. Philadelphia: Author.

Consortium for Policy Research in Education. (1999). A close look at effects on classroom practice and student performance: A report on the fifth year of the Merck Institute for Science Education, 1997-98. Philadelphia: Author.

Consortium for Policy Research in Education. (2000). Deepening the work: A report on the sixth year of the Merck Institute for Science Education, 1998-99. Philadelphia: Author.

Consortium for Policy Research in Education. (2001). Steady work: A report on the seventh year of the Merck Institute for Science Education, 1999-2000. Philadelphia: Author.

Consortium for Policy Research in Education. (2002). A report on the eighth year of the Merck Institute for Science Education. Philadelphia: Author. 


\section{Appendix B. Additional Publications about the Merck Institute for Science Education}

The following publications are available by contacting (215) 573-0700, extension 1 or via email at cpre@gse.upenn.edu.

Consortium for Policy Research in Education. (2003). Systemic reform in practice: Merck Institute for Science Education. Philadelphia: Author.

Corcoran, T. B. (2003). The Merck Institute for Science Education: A successful intermediary for educational reform. Philadelphia: Consortium for Policy Research in Education, University of Pennsylvania.

Corcoran, T. B., \& Lawrence, N. (2003). Changing district culture and capacity: The impact of the Merck Institute for Science Education partnership. Philadelphia: Consortium for Policy Research in Education, University of Pennsylvania.

Kannapel, P. J. (2003). Three Bridges and Holland Brook Elementary Schools, Readington Township, NJ. Philadelphia: Consortium for Policy Research in Education, University of Pennsylvania.

McVay, S. (2003). Franklin Elementary School, Rahway, NJ. Philadelphia: Consortium for Policy Research in Education, University of Pennsylvania.

McVay, S. (2003). Inglewood Elementary School, Lansdale, PA. Philadelphia: Consortium for Policy Research in Education, University of Pennsylvania.

Passantino, C. (2003). Highland Avenue School, Linden, NJ. Philadelphia: Consortium for Policy Research in Education, University of Pennsylvania.

Riordan, K. (2003). Teacher leadership as a strategy for instructional improvement: The case of the Merck Institute for Science Education. Philadelphia: Consortium for Policy Research in Education, University of Pennsylvania. 